\title{
Regional Saharan dust modelling during the SAMUM 2006 campaign
}

\author{
By BERND HEINOLD ${ }^{1 *}$, INA TEGEN ${ }^{1}$, MICHAEL ESSELBORN $^{2}$, KONRAD KANDLER $^{3}$, \\ PETER KNIPPERTZ ${ }^{4}$, DETLEF MÜLLER ${ }^{1}$, ALEXANDER SCHLADITZ ${ }^{1}$, \\ MATTHIAS TESCHE ${ }^{1}$, BERNADETT WEINZIERL ${ }^{2}$, ALBERT ANSMANN ${ }^{1}$, DIETRICH \\ ALTHAUSEN ${ }^{1}$, BENOIT LAURENT $^{1}$, ANDREAS MASSLING ${ }^{1,5}$, THOMAS MÜLLER ${ }^{1}$, \\ ANDREAS PETZOLD ${ }^{2}$, KERSTIN SCHEPANS KI I,6 and ALFRED WIEDENSOHLER ${ }^{1}$, \\ ${ }^{1}$ Leibniz Institute for Tropospheric Research, Leipzig, Germany; ${ }^{2}$ Deutsches Zentrum für Luft- und Raumfahrt (DLR), \\ Institut für Physik der Atmosphäre, Oberpfaffenhofen, Germany; ${ }^{3}$ Institute of Applied Geosciences, Darmstadt \\ University of Technology, Darmstadt, Germany; ${ }^{4}$ Institute for Atmospheric Physics, Johannes Gutenberg University \\ Mainz, Mainz, Germany; ${ }^{5}$ National Environmental Research Institute, Aarhus University, Roskilde, Denmark; ${ }^{6}$ Leibniz \\ Institute for Marine Sciences, IfM-Geomar, Kiel, Germany
}

(Manuscript received 8 January 2008; in final form 11 August 2008)

\begin{abstract}
The regional dust model system LM-MUSCAT-DES was developed in the framework of the SAMUM project. Using the unique comprehensive data set of near-source dust properties during the 2006 SAMUM field campaign, the performance of the model system is evaluated for two time periods in May and June 2006. Dust optical thicknesses, number size distributions and the position of the maximum dust extinction in the vertical profiles agree well with the observations. However, the spatio-temporal evolution of the dust plumes is not always reproduced due to inaccuracies in the dust source placement by the model. While simulated winds and dust distributions are well matched for dust events caused by dry synoptic-scale dynamics, they are often misrepresented when dust emissions are caused by moist convection or influenced by small-scale topography that is not resolved by the model. In contrast to long-range dust transport, in the vicinity of source regions the model performance strongly depends on the correct prediction of the exact location of sources. Insufficiently resolved vertical grid spacing causes the absence of inversions in the model vertical profiles and likely explains the absence of the observed sharply defined dust layers.
\end{abstract}

\section{Introduction}

As one of the major components of the atmospheric aerosol load, mineral dust emitted from desert soils by wind erosion plays an important role in the Earth's climate system. The presence of dust changes the global and regional energy balance, modifying atmospheric heating rates, temperatures and stability as well as the hydrological cycle (e.g. Sokolik and Toon, 1996; Myhre et al., 2003; Miller et al., 2004; Yoshioka et al., 2007). Considerable uncertainties in quantification of the highly variable distribution and optical properties of dust particles result in large uncertainties in estimates of the magnitude and even the sign of the dust effects (IPCC, 2007). The Saharan desert is the largest dust source worldwide, providing at least $50 \%$ to the global atmospheric dust load (Washington et al., 2003). To

\footnotetext{
* Corresponding author. e-mail: heinold@tropos.de DOI: $10.1111 / \mathrm{j} .1600-0889.2008 .00387 . \mathrm{x}$
}

improve the quantification of optical properties and radiative effects by Saharan dust, the research group SAharan Mineral dUst experiMent (SAMUM; Heintzenberg, 2008) carried out a field campaign in Morocco in May and June 2006. Scientists from six German universities and research institutes measured dust properties by ground-based, air-borne and space-borne remote sensing and analysed microphysical, chemical, and morphological properties of dust aerosol from field samples (see also http://samum.tropos.de). Compared to global models of the dust cycle, regional modelling allows to compute surface properties and transport processes at scales that are small enough to resolve more of the meteorological processes controlling dust processes (Zender et al., 2003). Within the framework of SAMUM we developed a regional model-system to describe Saharan dust emission, transport and deposition, together with its effect on the radiation balance (Heinold et al., 2007). To evaluate the model performance and its sensitivity to dust optical properties, simulations of far-field dust transport were carried out for two cases of strong dust transport episodes from the Saharan desert to 
Europe that were observed in August and October 2001, respectively (Heinold et al., 2007; Helmert et al., 2007) and of a case study in the vicinity of a dust source in the Bodélé depression (Tegen et al., 2006). On one hand this regional dust model provides a spatio-temporal context to the individual measurements taken during the SAMUM field experiment, supporting their interpretation. It can also be used for studying the dust radiative effect on regional meteorological parameters. On the other hand, the measurements taken near the dust source regions allow for a detailed evaluation of the regional dust model system, because many different and independent observations are available to test the validity of model parametrizations. Here we make use of a variety of measurements taken during the SAMUM dust experiment for a comprehensive model evaluation. The ability of the model to reproduce the main aspects of Saharan dust particles near their source region shows to which extent the model will be useful for obtaining reliable estimates of feedbacks between Saharan dust aerosol particles and meteorology.

\section{Model description}

The regional dust model LM-MUSCAT-DES that was developed in the framework of SAMUM is described in detail in Heinold et al. (2007). The dust emission scheme (DES) implemented in the model is based on Tegen et al. (2002). Surface properties like vegetation and snow cover, surface roughness, soil size distribution and soil moisture content as well as the location of preferential dust sources are considered for calculation of the dust emission flux $F\left(\mathrm{~kg} \mathrm{~m}^{-2} \mathrm{~s}^{-1}\right)$. Soil erosion by wind mostly depends on the wind shear stress on the ground and occurs when the surface friction velocity $u_{*}$ increases above a certain threshold friction velocity $u_{* t}$. The emission fluxes $F$ are computed as

$$
\begin{aligned}
F= & \alpha \frac{\rho_{a}}{g} u_{*}^{3} \sum_{i}\left[\left(1+\frac{u_{* t}\left(D_{p_{i}}\right)}{u_{*}}\right)\left(1-\frac{u_{* t}^{2}\left(D_{p_{i}}\right)}{u_{*}^{2}}\right) \Delta s_{i}\right] \\
& \times A_{\text {eff }}\left(1-A_{\text {snow }}\right) I_{\Theta},
\end{aligned}
$$

where $\alpha$ is the ratio between dust flux and horizontal saltation flux (sandblasting efficiency), $\rho_{a}$ denotes the air density, $g$ is the gravitational constant, $u_{*}$ is the surface friction velocity, $u_{* t}$ is the threshold friction velocity depending on the soil particle diameter $D_{p_{i}}$ of size fraction $i . u_{* t}$ was lowered by a factor of 0.66 in order to compensate for lower model winds (Heinold et al., 2007). The relative surface area covered by a size fraction is represented by $s_{i}, I_{\Theta}$ is the influence of soil moisture, $A_{\text {eff }}$ is the erodible area depending on the seasonal variations in vegetation cover and $A_{\text {snow }}$ is the part of $A_{\text {eff }}$ covered by snow.

In the model, the soil size distribution is represented by four populations (clay, silt, medium/fine and coarse sand), whose proportion is derived from soil texture data of the top $30 \mathrm{~cm}$ of dominant soil (Zobler, 1986). The soil size classes are assumed to be lognormally distributed with mode diameters at 2 , 15,158 and $720 \mu \mathrm{m} . u_{*}$ is computed using model first layer winds $U_{1 s t}$ and high-resolved roughness lengths $z_{0}$ from remote sensing (Marticorena et al., 2004) for northern Africa under the assumption of neutral atmospheric conditions

$u_{*}=U_{1 s t} \kappa\left[\ln \left(\frac{z_{1 s t}}{z_{0}}\right)\right]^{-1}$,

where $\kappa$ is the von Karman constant and $z_{1 s t}$ is the centre height of the first layer. The threshold friction velocities for dust emission are calculated as function of soil particle size distribution following Marticorena and Bergametti (1995). The sandblasting efficiency depends on soil texture and ranges from $\alpha=$ $10^{-7} \mathrm{~cm}^{-1}$ for coarse sand or clay soils, to $\alpha=10^{-5} \mathrm{~cm}^{-1}$ in gridcells considered as preferential dust sources (Tegen et al., 2002). Thus the size distribution of the mobilised dust both reflects the soil size spectrum and its dependence on surface winds. Preferential source areas, so called 'hot-spots', are assumed to coincide with enclosed topographic depressions, for example, the Bodélé (Prospero et al., 2002). Their location and extent were derived from a hydrological model (Tegen et al., 2002).

For the description of dust transport, deposition and radiation processes, the parallelised regional model system LM-MUSCAT is used. It is composed of the non-hydrostatic Lokal-Modell (LM; Doms and Schättler, 2002) now renamed COSMO, which is operationally run for weather forecast by the German weather service (Deutscher Wetterdienst, DWD) as meteorological driver, and the online-coupled multiscale 3-D chemistry transport model MUltiScale Chemistry Aerosol Transport Model (MUSCAT; Wolke et al., 2004a,b). MUSCAT is based on time-dependent mass balance equations describing microphysical processes and chemical reactions. Advection is computed by a third-order upstream scheme, and an implicitexplicit scheme is applied for the time integration (Knoth and Wolke, 1998; Wolke and Knoth, 2000). Emission and transport of mineral dust are calculated on the basis of meteorological and hydrological conditions updated every advection time step comprising two LM time steps (45 s). Local wind systems, clouds, precipitation and mesoscale convection are simulated depending on topography, subgridscale moist convection is parametrized following Tiedtke (1989). The DES that computes dust emission fluxes using LM surface winds and soil moisture is implemented in LM-MUSCAT. The model transports dust as a passive tracer in five independent size classes with diameter limits at $0.2,0.6,1.7,5.3,16$ and $48 \mu \mathrm{m}$. The aerosol deposition parametrisation in LM-MUSCAT is adapted with respect to dust particle density and washout efficiency. Dry deposition of dust is parametrised as proposed by Zhang et al. (2001). For particles larger than $2 \mu \mathrm{m}$ the removal from the atmosphere is mainly by gravitational settling. Wet deposition, both incloud and sub-cloud removal, is parametrized following Berge (1997) and Jakobson et al. (1997). Optical thickness at $550 \mathrm{~nm}$ wavelength is computed from the model dust concentration as

$\tau=\sum_{j} \sum_{k}\left(\frac{3}{4} \frac{Q_{\mathrm{ext}, 550}(j)}{r_{\mathrm{eff}}(j) \rho_{p}(j)} c_{\mathrm{dust}}(j, k) \Delta z(k)\right)$, 
where $Q_{\text {ext, } 550}(j)$ is the extinction efficiency at $550 \mathrm{~nm}$ of the dust mode $j, r_{\text {eff }}(j)$ is the effective radius of dust particles of mode $j, c_{\text {dust }}(j, k)$ is the dust concentration of the dust mode $j$ at the vertical level $k$, and $\Delta z(k)$ is the increment of each vertical level $k$. For the evaluation of the simulated dust distribution, the extinction efficiency $Q_{\text {ext, } 550}(j)$ is calculated from Mie theory using dust refractive indices from Sinyuk et al. (2003) and is 1.677 for the smallest dust mode, 3.179, 2.356, 2.144 and 2.071 for the larger size classes, respectively. Mie calculations require the assumption of spherical particles, which is not reasonable for most dust particles. However, the errors in radiative flux computation are small in the hemispherical integration when compared to computations with spheroids (Lacis and Mishchenko, 1995). The differences between the optical properties from Sinyuk et al. (2003) and those used in the LM for radiative feedback simulations may be crucial for estimates of dust radiative effects, but are less important for testing the model performance (Helmert et al., 2007). The performance of this regional dust model has previously been successfully tested for two well-documented periods of Saharan dust transport to Europe in August and October 2001 (Heinold et al., 2007), and for a dust outbreak over the Bodélé depression in 2005 (Tegen et al., 2006).

\subsection{Dust radiative feedback}

Dust aerosol in LM-MUSCAT-DES interacts with the LM radiation scheme such that the direct radiative effect by dust influences the atmospheric dynamics in the regional model. The dependency of this dust feedback in LM on the prescribed dust optical properties has been described by Helmert et al. (2007). The radiation scheme of the LM uses a $\delta$-two-stream radiative transfer solver with three solar and five thermal spectral bands and considers effects of scattering, absorption and emission by gases, cloud droplets and aerosols (Ritter and Geleyn, 1992). For simulations of the Saharan dust cycle including online dust radiative effects, the climatologically fixed distribution of desert dust that is part of the LM aerosol climatology (Tanré et al., 1984) is replaced by the modelled size-resolved dust load from the transport model and optical properties computed by Mie theory. In this way, the radiation scheme accounts for the spatio-temporal variability of atmospheric dust load. The spectral refractive indices from laboratory measurements performed by Sokolik and Toon (1999) were used, assuming an internal mixture of $2 \%$ hematite and $98 \%$ kaolinite with the real part of the dust refractive index of 1.52 and the imaginary part of $5.8 \times 10^{-3}$ at $550 \mathrm{~nm}$. The spectral distribution of the single scattering albedo for the LM radiation bands is shown in Table 1 for the effective dust radii representative for the individual size bins.

These optical properties have to be considered as a preliminary estimate. The findings from the SAMUM field campaign will be used to update the wavelength-dependent optical properties of Saharan dust in future model experiments. Especially
Table 1. Mie-derived single scattering albedo ${ }^{a)} \omega_{0}$ of Saharan dust used for the different radiation bands of LM as a function of dust effective radius $r_{e}$ (modified from Helmert et al., 2007)

\begin{tabular}{lcccccc}
\hline & & \multicolumn{5}{c}{ Effective radius $r_{e}(\mu \mathrm{m})$} \\
\cline { 3 - 7 }$\#$ & Spectral band $(\mu \mathrm{m})$ & 0.17 & 0.5 & 1.5 & 4.6 & 13.8 \\
& $\omega_{0} \rightarrow$ & & & & \\
\hline 1 & $0.245-0.7$ & 0.960 & 0.901 & 0.793 & 0.685 & 0.606 \\
2 & $0.7-1.53$ & 0.992 & 0.995 & 0.981 & 0.952 & 0.883 \\
3 & $1.53-4.642$ & 0.824 & 0.952 & 0.970 & 0.921 & 0.849 \\
4 & $4.642-8.333$ & 0.006 & 0.087 & 0.317 & 0.471 & 0.483 \\
5 & $8.333-9.009$, & 0.003 & 0.058 & 0.358 & 0.520 & 0.543 \\
& $10.309-12.5$ & & & & & \\
6 & $9.009-10.309$ & 0.006 & 0.105 & 0.421 & 0.569 & 0.631 \\
7 & $12.5-20.0$ & 0.000 & 0.010 & 0.165 & 0.442 & 0.543 \\
8 & $20.0-104.515$ & 0.000 & 0.004 & 0.083 & 0.408 & 0.496 \\
\hline
\end{tabular}

a) The single scattering albedos are spectrally integrated values over the wavelength range of the corresponding spectral band.

the dependency of the dust refractive index on the source regions that was observed during the field campaign (Petzold et al., 2008) will require to prescribe dust optical properties with respect to dust origin. In SAMUM, the complex dust refractive index was derived from airborne (Petzold et al., 2008), ground-based and laboratory (Müller et al., 2008b; Schladitz et al., 2008) measurements of particle size distributions as well as aerosol absorption and scattering coefficients (the latter was directly measured only for near-surface samples). In addition, dust optical properties were determined from the chemical and mineralogical composition of aerosol samples collected at the ground and during research flights (Kandler et al., 2008). Depending on the different methods and dust episodes the real part of the refractive index of dust varies between 1.53 and 1.56, and the imaginary part ranges from about $1.5 \times 10^{-3}$ to 8.5 $\times 10^{-3}$ at 537 or $550 \mathrm{~nm}$, respectively (Table 2). At surface, low dust loads in particular were influenced by soot aerosol. After separation of the soot absorption for the ground-based observations, the imaginary part varies between $1.5 \times 10^{-3}$ and $2.6 \times 10^{-3}$ at $550 \mathrm{~nm}$ (Müller et al., 2008b), which indicates less absorption than the Sokolik and Toon (1999) values. Correcting the indices for soot absorption, the imaginary part of the refractive index clearly shows the spectral signature of hematite (Müller et al., 2008b). In Petzold et al. (2008) and Müller et al. (2008b) the dust optical properties obtained from the different measurements during SAMUM are discussed in detail including a comparison to data reported in the literature. The comparison of the values of imaginary refractive index of north Saharan dust indicates that the dust is slightly too absorbing in the model. The values used in the model are, however, within the range of measurements of the dust samples that were not corrected for soot content. 
Table 2. Real $\operatorname{Re}(n)$ and imaginary $\operatorname{Im}(n)$ parts of the refractive indices $n$ for mineral dust from the north-western Sahara derived from measurements during the 2006 SAMUM field campaign (wavelengths in parentheses). Data collected aboard Falcon aircraft are indicated by 'airborne'; 'ground' refers to ground-based measurements at Tinfou. Müller et al. (2008b) assume $\operatorname{Re}(n)=1.53$, which is a common value given in literature. The high variability of the imaginary part of the complex refractive indices is primarily due to different dust source regions. For comparison the dust refractive index from Sokolik and Toon (1999) (internal mixture of $2 \%$ hematite and $98 \%$ kaolinite) as used in the interactive dust simulations with LM-MUSCAT-DES is given

\begin{tabular}{lcccc}
\hline Reference & $\operatorname{Re}(n)$ & $\operatorname{Im}(n)$ & Size range $(\mu \mathrm{m})$ & Remarks \\
\hline Petzold et al. (2008) & $1.55-1.56$ & $1.6-4.2 \times 10^{-3}(550 \mathrm{~nm})$ & $0.004-100$ & In situ, airborne \\
Kandler et al. (2008) & $1.56-1.58$ & $2.7-6.6 \times 10^{-3}(530 \mathrm{~nm})$ & $0.7-3$ & Dust samples, airborne \\
Kandler et al. (2008) & $1.55-1.57$ & $2.6-4.2 \times 10^{-3}(530 \mathrm{~nm})$ & $0.1-250$ & Dust samples, ground \\
Müller et al. (2008b) & 1.53 & $3.2-5.5 \times 10^{-3}(550 \mathrm{~nm})$ & $0.02-10$ & In situ, ground, total \\
Müller et al. (2008b) & 1.53 & $1.5-2.6 \times 10^{-3}(550 \mathrm{~nm})$ & $0.5-10$ & In situ, ground, soot corrected \\
Schladitz et al. (2008) & 1.53 & $2.9-8.5 \times 10^{-3}(537 \mathrm{~nm})$ & $0.02-10$ & In situ, ground \\
Sokolik and Toon (1999) & 1.52 & $5.8 \times 10^{-3}(550 \mathrm{~nm})$ & & Interactive dust simulations \\
\hline
\end{tabular}

A test of the model sensitivity to dust optical properties derived from in situ measurements, remote sensing, bulk measurements and laboratory experiments in the literature is given in Helmert et al. (2007). They showed that the magnitude of dust radiative effects can vary by up to $25 \%$ depending on the dust optical properties used.

\subsection{Model setup}

For simulations of the dust episodes during the SAMUM field campaign, a horizontal resolution of $14 \mathrm{~km}$ was used for the area between the coordinates $14.09^{\circ} \mathrm{N} ; 20.36^{\circ} \mathrm{W}$ (lower left-hand corner) and $39.09^{\circ} \mathrm{N} ; 34.29^{\circ} \mathrm{E}$ (upper right-hand corner) as well as a horizontal resolution of $28 \mathrm{~km}$ for the area between $13.86^{\circ} \mathrm{N}$; $25.35^{\circ} \mathrm{W}$ (lower left-hand corner) and $47.78^{\circ} \mathrm{N} ; 38.16^{\circ} \mathrm{E}$ (upper right-hand corner). Both model domains cover major parts of the Sahara desert and southern or central Europe, respectively, ensuring that synoptic and regional scale weather systems, dust transport to the experimental site and local dust emissions are taken into account. By means of the two resolutions the model sensitivity on the grid spacing was tested. Since the results were quite similar, here only parameters from the run with $28 \mathrm{~km}$ horizontal resolution are presented, except for the vertical dust distribution. The model is operated with 40 vertical layers of a pressure-based, terrain following vertical coordinate. The lowest layer reaches $68 \mathrm{~m}$ above surface.

Simulations were performed for the period from 9 May to 5 June, 2006. Here, we focus on the results for the days of 19-20 May and 3-4 June 2006, when dust events were observed by many airborne and ground-based instruments during the SAMUM field experiment. The LM runs are initialized using analysis fields from the global model GME (Majewski et al., 2002), and driven by 6-hourly updated lateral boundary conditions from the GME. The simulations were carried out in cycles with a re-initialization every $48 \mathrm{~h}$ in order to keep the meteorology of the regional model close to the analysis fields. After a spin-up period of $24 \mathrm{~h}$ the LM is coupled with MUSCAT to compute dust mobilisation and transport. The initial dust concentration at the first cycle is set to zero. The following cycles use the modelled dust concentration from the previous cycle as initialisation.

\subsection{Observations used for model validation}

The SAMUM field campaign took place in southern Morocco during 12 May and 8 June 2006. Numerous in situ and remote sensing observations were collected at two ground stations, Ouarzazate airport $\left(30.93^{\circ} \mathrm{N} ; 6.90^{\circ} \mathrm{W}\right)$ and Tinfou $\left(30.25^{\circ} \mathrm{N}\right.$; $5.62^{\circ} \mathrm{W}$ ). Two aircrafts (Falcon, Partenavia) were used over the ground sites to complement the ground-based measurements characterising the dust-filled atmospheric column. In this study we make use of (1) the particle aerosol optical thickness (AOT) measured at Ouarzazate with an Aerosol Robotic Network (AERONET; Holben et al., 1998) sunphotometer (CIMEL Electronique 318A spectral radiometer), which measures sun and sky radiances at seven wavelengths (340-1640 nm) (D. Müller, personal communication, 2008). Here, only AOTs at $500 \mathrm{~nm}$ are considered. (2) Profiles of the 532-nm extinction coefficient from the six-wavelength aerosol lidar Backscatter Extinction lidar-Ratio Temperature Humidity profiling Apparatus (BERTHA) of the Leibniz Institute for Tropospheric Research (IfT) (Althausen et al., 2000; Tesche et al., 2008) are used to validate the vertical profiles of the modelled dust over Ouarzazate. These lidar data have a temporal resolution of $30 \mathrm{~s}$ and a vertical resolution of $60 \mathrm{~m}$. (3) The model-derived dust size distribution is compared with near-surface particle number size distributions for particles with diameters between $20 \mathrm{~nm}$ and $500 \mu \mathrm{m}$ measured at Tinfou. The particle diameter size range of $20 \mathrm{~nm} \leq D \leq 10 \mu \mathrm{m}$ was measured quasi-continuously by the combination of a Differential Mobility Particle Sizer (DMPS) and an Aerodynamic Particle Sizer (APS), particles with $4 \mu \mathrm{m} \leq D \leq 500 \mu \mathrm{m}$ were measured by impactor collection on 
coated glass substrates once a day (Kandler et al., 2008; Schladitz et al., 2008). Several flight experiments were conducted to measure the vertical distribution of dust above the observation sites. The Falcon aircraft of the German Aerospace Center (Deutsches Zentrum für Luft-und Raum-fahrt, DLR) carried instrumentation for measuring (4) dust particle size distributions in the size range of $4 \mathrm{~nm} \leq D \leq 100 \mu \mathrm{m}$. Here, the parametrised size distributions form combined measurements using Condensation Particle Counters (CPCs) and several Optical Particle Counters (OPCs) (Weinzierl et al., 2008) are taken for comparisons with modelled size distributions at different heights. (5) The airborne nadir-looking High Spectral Resolution Lidar (HSRL) on board the Falcon provided vertical slices of extinction and backscatter coefficients at $532 \mathrm{~nm}$ (Esselborn et al., 2008), which are compared to the model-derived dust backscatter coefficients along the flight paths. For the validation of the meteorology simulated by LM, soundings of wind speed and thermodynamical properties (6) measured aboard the Falcon and (7) from Vaisala radiosondes (type RS92), which were launched at Ouarzazate, are used.

The spatio-temporal distribution of modelled dust optical thickness is also qualitatively compared to satellite retrievals of the absorbing aerosol index (AI) from the Ozone Monitoring Instrument (OMI) (Levelt, 2002), which is an indicator for the presence of absorbing aerosol particles including dust. The OMI AI data set is screened for clouds taking into account only grid cells where the reflectivity at $380 \mathrm{~nm}$ was $<12 \%$. A cloud screening is also applied to the model results. Gridpoints are removed if the fractional cloud cover simulated by LM (Doms and Schättler, 2002) exceeds $75 \%$. The recently developed infrared dust index computed from brightness temperature differences of three infrared (IR) channels of the geostationary Meteosat Second Generation (MSG) satellite (Schmetz et al., 2002; http://www.eumetsat.int) is useful to identify dust sources (Schepanski et al., 2007) and is used as an additional qualitative indicator for the presence of dust. For a quantitative validation, the model-derived dust AOTs are additionally compared with quality-assured and cloud-screened AOT data from three other AERONET stations: Tamanrasset $\left(22.79^{\circ} \mathrm{N}\right.$; $\left.5.53^{\circ} \mathrm{E}\right)$, Saada $\left(31.63^{\circ} \mathrm{N} ; 8.16^{\circ} \mathrm{W}\right)$ and Lampedusa $\left(35.52^{\circ} \mathrm{N}\right.$; $\left.12.63^{\circ} \mathrm{E}\right)$. As the sunphotometer measurements represent AOTs of the total aerosol column, we added a constant value for the background aerosol (excluding dust) to the model results for dust optical thickness. These values (Tamanrasset: 0.169; Saada: 0.171; Ouarzazate: 0.169; Lampedusa: 0.211) are taken from the aerosol climatology used in the LM radiation scheme (Tanré et al., 1984), which may overestimate the contribution of tropospheric background aerosol at least at Tamanrasset and Ouarzazate, where mineral dust dominates. We also compared meteorological parameters from the regional model to standard meteorological measurements from Tamanrasset $\left(22.79^{\circ} \mathrm{N}\right.$; $\left.5.53^{\circ} \mathrm{E}\right)$, El Golea $\left(30.57^{\circ} \mathrm{N} ; 2.87^{\circ} \mathrm{E}\right)$ and Bechar $\left(31.15^{\circ} \mathrm{N}\right.$; $2.25^{\circ} \mathrm{W}$ ) distributed by the World Meteorological Organisation
(WMO) as well as observations from IMPETUS (An integrated approach to the efficient management of scarce water resources in West Africa; Speth and Diekkrüger, 2006) network stations in southern Morocco: Iriki $\left(29.97^{\circ} \mathrm{N} ; 6.35^{\circ} \mathrm{W}\right)$, El Miyit $\left(30.36^{\circ} \mathrm{N}\right.$; $\left.5.63^{\circ} \mathrm{W}\right)$, Taoujgalt $\left(31.39^{\circ} \mathrm{N} ; 6.32^{\circ} \mathrm{W}\right)$.

\section{Results}

Knippertz et al. (2008) describe the meteorological situations of the main dust episodes occurring in Morocco during the SAMUM field experiment in detail. For the regional dust model evaluation we focus on the two episodes of 16-22 May 2006 and 31 May-4 June 2006 [Intermediate Phase 1 (IP1), Dust Phase 2 (DP2) and Dust Phase 3 (DP3), respectively, in Knippertz et al. (2008)], which represent different meteorological situations responsible for dust mobilisation.

\subsection{Dust distribution during 16-22 May and 31 May-4 June 2006}

The episode 16-22 May was characterised by calm weather conditions at the beginning and strong moist convective activity including occurrence of density currents at the end. On 15-17 May an upper-level ridge established over north-western Africa, with a surface high centred over the eastern Atlas. In this situation, moderately dusty air was transported from eastern and central Algeria towards Morocco (Knippertz et al., 2008). The spatio-temporal evolution of the dust distribution is illustrated for the days 16, 18 and 20 May (at 12:00 UTC) in Fig. 1 for modelled optical thickness at $550 \mathrm{~nm}$, retrievals of OMI AI and the MSG infrared dust index, together with dust emissions simulated for the previous day. Blue areas indicate cloudiness that obscured the dust plume below. The comparison of modelled dust optical thickness with these satellite indices can only be qualitative, as no quantitative dust information can be obtained over land from remote sensing with these instruments yet. As shown by OMI AI and MSG dust index, on 16 May dust aerosol occurred in central Algeria. The dust was advected in easterly directions towards the Moroccan coast and from there further northwards in an anticyclonic motion around the surface high over the eastern Atlas, forming an arc-shaped dust plume over Morocco and the Iberian Peninsula (Fig. 1a). In Algeria, dust sources are also activated in the model on 15 and 16 May (Fig. 1j). While the dust emission west of the Tademait Plateau, which is evident in the OMI AI and MSG dust index retrievals (Figs. 1a and g, respectively), appears to be overestimated, the anticyclonic transport patterns are well reproduced by the model (Fig. 1d). In addition, the OMI AI indicates dust emissions in southwestern and central Libya, in eastern Mauritania as well as near the border of Mali and Niger. Compared to the observations these sources are partly described by the model, although not always at the correct location. Despite dust emissions, the dust load over Mauritania and Libya remains quite low in the model results. On 18 May again the dust production west of the 
16 May 2006 18 May 2006 20 May 2006


Fig. 1. Comparison of the horizontal distribution of Saharan dust at 12:00 UTC on days: 16, 18 and 20 May 2006. Map of OMI AI (overpass at 13:45 local time; a-c), model-derived dust aerosol optical thickness at $550 \mathrm{~nm}(\mathrm{~d}-\mathrm{f})$, MSG dust index ( $\mathrm{g}-\mathrm{i}$ ), and modelled dust emission fluxes for the previous $24 \mathrm{~h}(\mathrm{j}-1)$. Note that the colour bar describes different units. In the MSG product, dust is indicated by pink colour. Black dots indicate the position of the SAMUM sites Tinfou (1) and Ouarzazate (2), the AERONET stations Saada (3), Tamanrasset (5) and Lampedusa (6), as well as the location of Casablanca (4).

Tademaï Plateau is correctly placed in the model but may be too pronounced. The model simulates dust production in eastern Mali, southern Algeria, Niger and in the Bodélé (Fig. 1k). These regions are partly obscured by clouds, but the source activation in Niger is confirmed by the MSG retrievals (Fig. 1h). In the night from 19 to 20 May, precipitation from deep convection over north-eastern Mali and associated evaporational cooling caused the formation of a large haboob, which quickly spread north- and westwards. On these days dust mobilisation mainly occurred over Mali (not shown). On 20 May at 12:00 UTC the dust plume was distributed over northern Mali, Mauritania and Algeria (Knippertz et al., 2008; see Figs. 1i and c). This dust 
source is strongly emitting in the model, but located too far to the west at the border of Mauritania and Mali compared to the satellite maps. As a consequence, the modelled dust is transported along the Atlantic coast and northern side of the Atlas mountain chain instead of being advected to both sides of the Atlas (cp. Figs. 1c and f). This discrepancy is caused by the inability of the
LM to represent the exact spatio-temporal distribution of moist convection in this case. Possibly, the standard LM moist convection scheme by Tiedtke (1989) is not suitable for the conditions in desert regions.

The second dust episode from 31 May to 4 June is illustrated in Fig. 2, again comparing model optical thickness results at
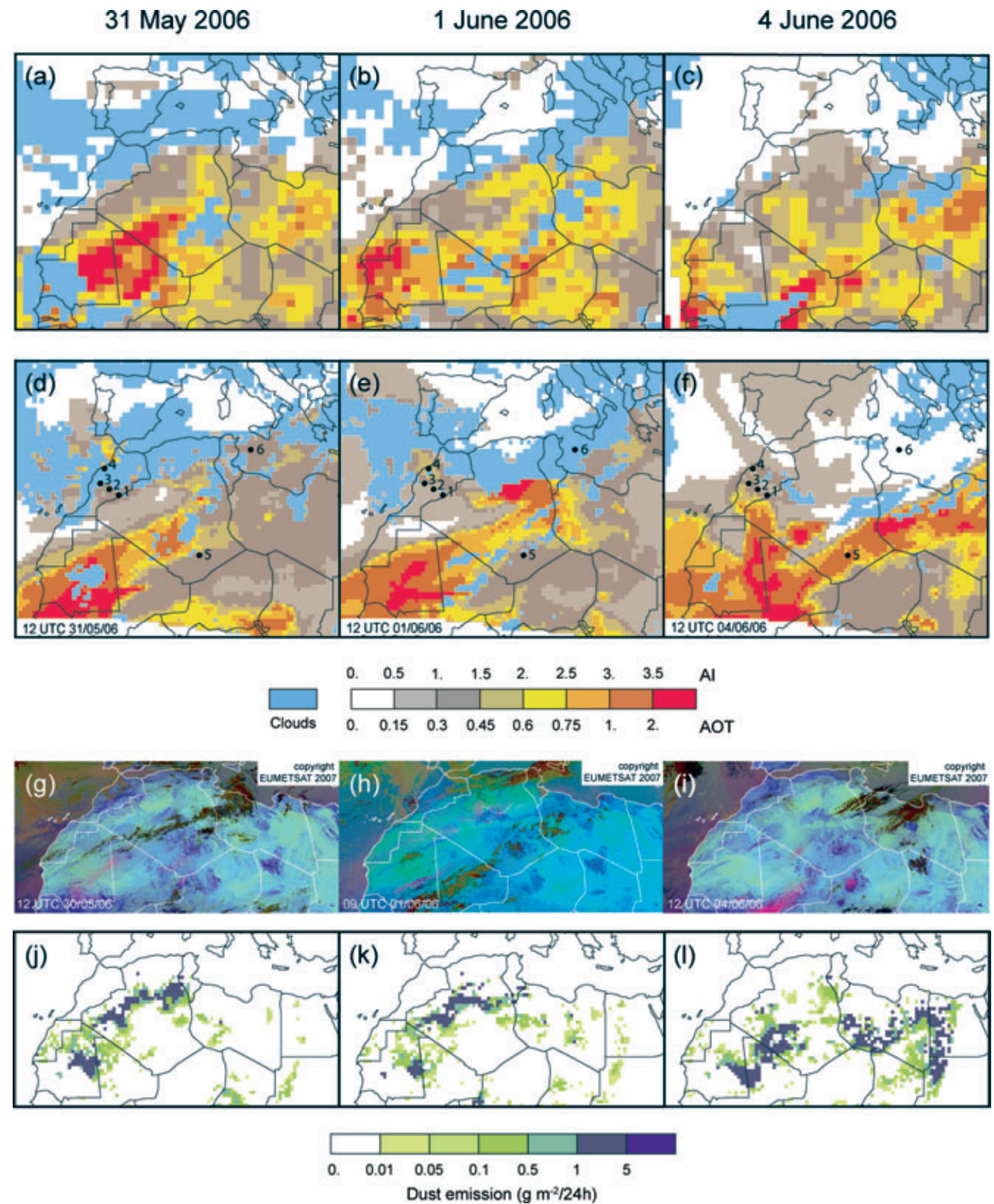

Fig. 2. Comparison of the horizontal distribution of Saharan dust at 12:00 UTC on days: 31 May, 1, and 4 June 2006. Map of OMI AI (overpass at 13:45 local time; a-c), model-derived dust aerosol optical thickness at $550 \mathrm{~nm}(\mathrm{~d}-\mathrm{f}$ ), MSG dust index (g-i, note: Fig. $2 \mathrm{~g}$ is for $30 \mathrm{May}$ ) and modelled dust emission fluxes for the previous $24 \mathrm{~h}(\mathrm{j}-1)$. Note that the colour bar describes different units. In the MSG product, dust is indicated by pink colour. The dust front associated with the cold surge on 1 June is highlighted by a dashed line (h). Black dots indicate the position of the SAMUM sites Tinfou (1) and Ouarzazate (2), the AERONET stations Saada (3), Tamanrasset (5) and Lampedusa (6), as well as the location of Casablanca (4). 
12:00 UTC with OMI AI, the MSG infrared dust index and dust emissions of the previous day for the days 31 May, 1 June and 4 June. During this dust episode a large upper-level trough over the central and eastern Mediterranean basin and a weaker ridge near the Iberian Peninsula controlled the upper-level circulation. On 31 May to 1 June a cut-off low moved from the Atlantic coast across the Atlas mountains, associated with the formation of a lee cyclone that travelled fast from Morocco to Libya along the Mediterranean coast. On 30 May a cloud band was present to the south of the Atlas chain, and the MSG product indicated the presence of dust over northwestern Mali and Mauritania (Fig. 2g). In the model, dust emissions are simulated over central Mauritania and Algeria (Fig. 2j). Dust production and associated high dust optical thicknesses can be seen in the OMI AI image and in the model results on 31 May in central Algeria, Mauritania and central Mali (Figs. 2a and d). On the western side of the lee cyclone cold air, which at first was blocked by the Algerian Atlas, surged from the Mediterranean across Tunisia into Algeria on 1 June. Dust was mobilised over the Chott areas in western Tunisia as well as over north-eastern and central Algeria (Knippertz et al., 2008). From 31 May to 1 June moist convection over the Atlas caused density currents in the southern Atlas foothills (Knippertz et al., 2007). In central Algeria, dust emission due to the spread of the cold surge on 1 June is shown by the MSG dust index and OMI AI retrievals (Figs. $2 \mathrm{~b}$ and $\mathrm{h}$ ). The model is able to reproduce the sources over central Algeria and the transport towards Morocco (Figs. 2e and $\mathrm{k})$. While the model overestimates a dust source at the eastern border of Algeria, dust sources in the foothills of the Ahaggar are not activated in the model (Figs. 2e and k). Therefore, dust optical thickness is underestimated over the Ahaggar. Moreover, in the model high dust optical thicknesses occurs in Mauritania and Mali, which are also indicated by the OMI AI. On 2 June northwestern Africa came under the influence of a strengthening upper-level ridge, which caused dust advection from easterly directions towards the Moroccan site (Knippertz et al., 2008). On 2 June, the model simulates dust emissions to the west of the Tademaït Plateau. Dust emissions in eastern Mali and near the eastern border of Mauritania are correctly simulated by the model (not shown). On 4 June the OMI AI retrieval shows a higher dust load over western Algeria, which was reproduced by the model (Figs. 2c and f). Dust production in the foothills of the Ahaggar was recorded by the MSG dust index in the morning of 4 June (Fig. 2i). This dust source is also activated in the model (Fig. 21). Dust emissions modelled in Libya were possibly associated with moist convection. While the model does not simulate dust emissions in Niger that are indicated in the OMI AI and MSG dust index retrievals, the modelled dust load over the southern foothills of the Ahaggar appears to be overestimated. Density currents observed by Knippertz et al. (2007) in the Atlas region on 2 to 4 June are not reproduced by the model.

\subsection{Dust optical thickness}

The modelled optical thicknesses for both time periods show in general a good agreement with sunphotometer measurements at the four locations Lampedusa, Ouarzazate, Saada and Tamanrasset (Fig. 3). Lampedusa is located in the Mediterranean, 133 $\mathrm{km}$ east from the Tunisian coast, and thus represents long-range transport of dust. It is not sensitive to the exact location of the source area. At this location both modelled temporal evolution and the magnitude of dust optical thicknesses agree very well with the sunphotometer measurements. For the SAMUM site Ouarzazate and the AERONET station Saada, which is located north of the High Atlas, the optical thicknesses during both time periods were around 0.5 . For the first $2 \mathrm{~d}$ of the period 16-22 May (Fig. 3, left-hand panels) the model overestimates the dust optical thickness as a consequence of too strong emissions in the northwest of the Tademait Plateau. Modelled dust optical thicknesses agree very well with the measurements at Ouarzazate for the remaining period. At Saada, north of the Atlas mountain chain, the model slightly underestimates the dust optical thickness on 18-20 May, because of the more westerly located dust source in the model and the resulting deviation in transport patterns (cp. Figs. 1c and f). The model results and observations agree well at Tamanrasset in the central Sahara for the first period, the dust optical thickness remains at values around 0.25 .

For the period 31 May to 4 June (Fig. 3, right-hand panels) model results and observations agree well for Ouarzazate and Saada for most of the period. At Ouarzazate, the model overestimates dust optical thicknesses, as unrealistically large dust emissions are simulated over south-western Algeria on 30 May, resulting in considerable dust transport to the Atlantic. At this location, on 3 June the model slightly underestimates the optical thickness measurements, as the dust emissions in western Algeria (Fig. 21) are probably underestimated. However, the comparison of OMI AI and model-derived dust optical thickness indicates that in the model the maximum dust load over western Algeria is located too far west when compared to the satellite dust indicators (see Figs. 2c and f). At Tamanrasset, the model slightly underestimates the dust optical thickness during 31 May to 2 June because of possibly missed or misplaced sources in eastern Mali, but then by far over-predicts dust loads during 3-5 June likely due to unrealistic dust emissions in southwestern Algeria.

\subsection{Vertical structure of the dust layer}

Besides the dust optical thickness of the atmospheric column, the vertical distribution of the dust aerosol is an important indicator for the ability of the model to reproduce transport patterns correctly. In addition, the vertical extent of a dust plume affects its radiative impact. Since characteristics of the planetary boundary 
Fig. 3. Comparison of the model-derived dust aerosol optical thickness $(440 \mathrm{~nm}$; bold line) with the optical thickness provided by AERONET at Lampedusa, Ouarzazate, Saada and Tamanrasset on 16-22 May 2006 (a-d) and 31 May-4 June $2006(\mathrm{e}-\mathrm{h})$. The grey-coloured area marks the background aerosol optical thickness added to the model results.
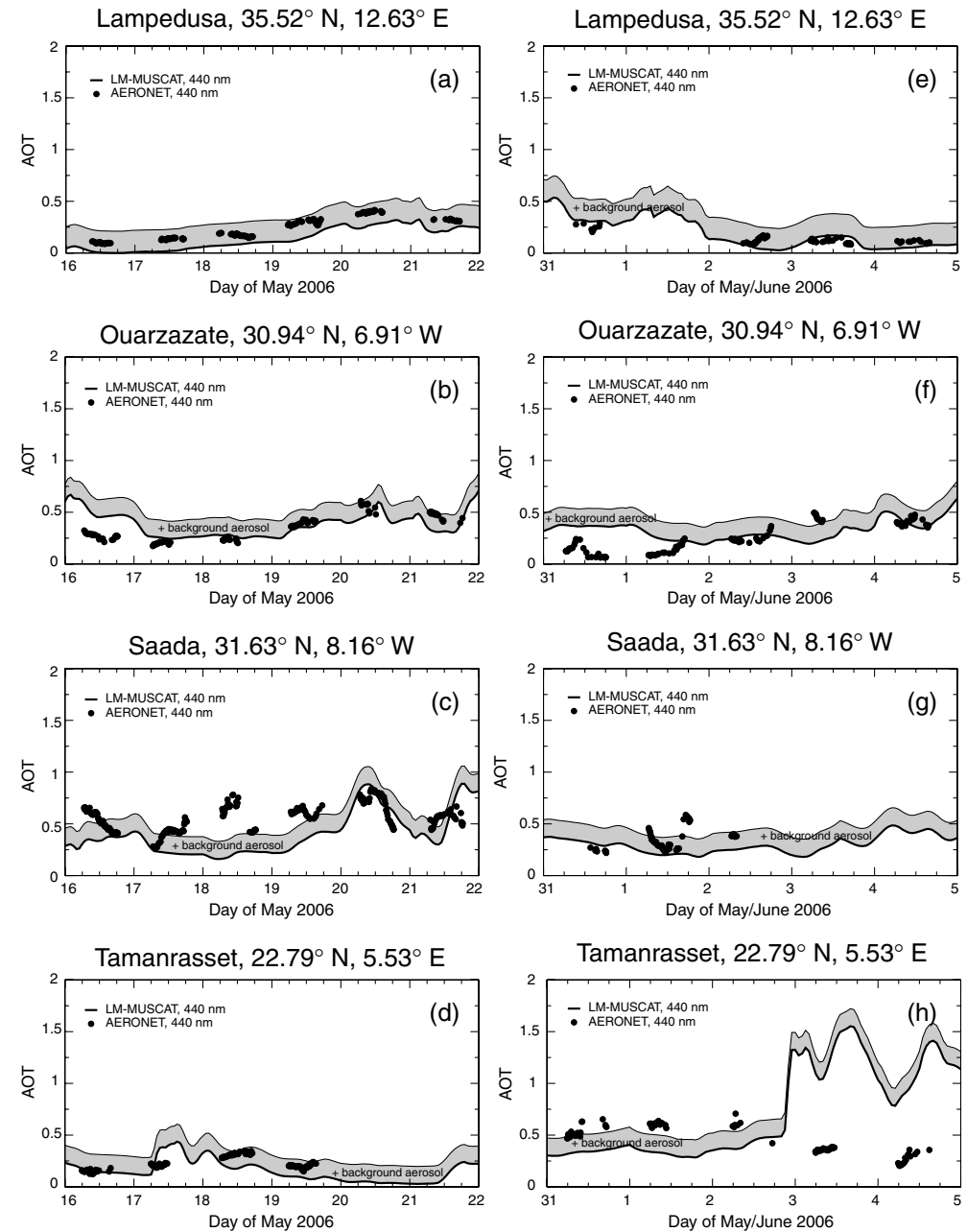

layer (PBL) mainly determine the dust vertical structure, first the vertical profiles of wind speed and temperature from the measurements taken during the Falcon flights over Casablanca airport and radiosonde ascents from Ouarzazate are compared with the model results. Figure 4 shows the corresponding profiles for the morning hours of 20 May (10:35 UTC and 10:45 UTC) and 4 June (9:20 UTC and 10:45 UTC). As repeatedly reported for many days during the field campaign, the PBL exhibited a layered structure. Such layers can occur when the mixed layer of the previous day is decoupled from the surface due to radiative cooling at night and remains as residual dust layer on the top of the nocturnal stable PBL. After sun rise the new mixed layer erodes the nocturnal residual layer (Knippertz et al., 2008). The vertical profiles of temperature show two or more layers with slightly increased thermal stability in the morning of 20 May and 4 June (Fig. 4). At Casablanca the influence of the adjacent Atlantic Ocean becomes evident; the land-sea wind circulation causes a near-surface inversion (Figs. 4a and c). The comparisons reveal that while the profiles of wind and temperature are generally well reproduced in the model, the observed rather weak inversions on both days and associated jumps in wind speed are missing. Pronounced, vertically limited wind maxima and minima are significantly under- and overestimated, respectively. The inability of the model to capture these sharp, vertically limited structures is mainly attributed to a too coarse vertical resolution of the model, but may be also related to numerical diffusion or an inappropriate boundary layer scheme providing a too efficient turbulent mixing. The differences in the temperature profile near the surface between model and observations at Casablanca Airport on 20 May are caused by a slightly different representation of the land-sea wind circulation in the model. The missing layers with increased stability in the model are the likely cause for the absence of a well-defined simulated dust layer top as shown in the following comparisons.

In the source region, modelled dust extinction coefficients are compared to lidar measurements taken during SAMUM at Ouarzazate for the days 18 and 19 May as well as 3 and 4 June (Fig. 5). Modelled extinction coefficients are compared to measurements by the IfT lidar at $532 \mathrm{~nm}$ wavelength. On 18 May (21:15 UTC) the observed extinction coefficient 

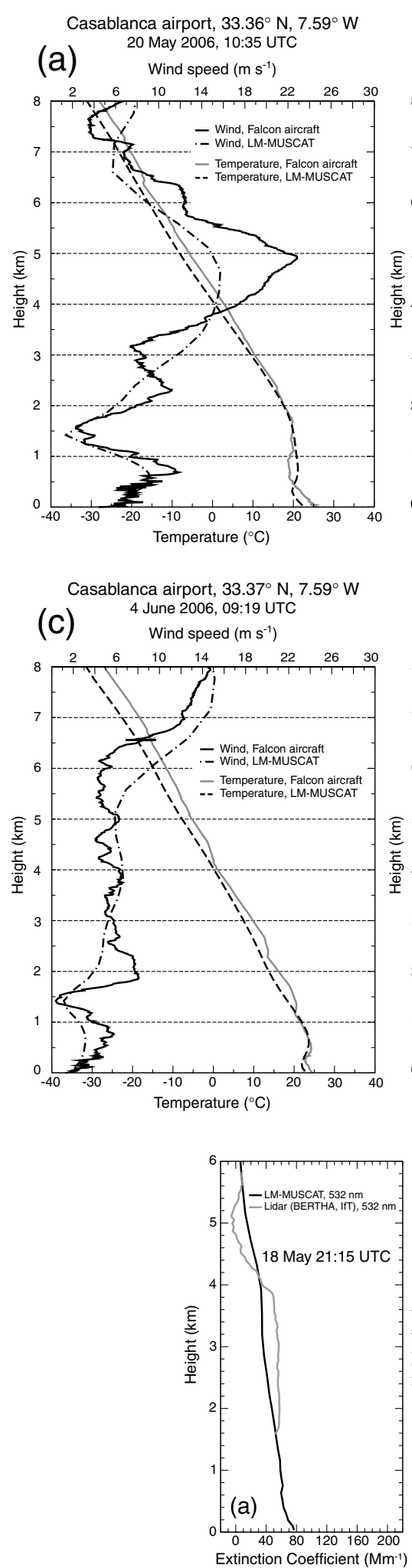

Ouarzazate, $30.93^{\circ} \mathrm{N}, 6.90^{\circ} \mathrm{W}$

(b) 20 May 2006, 10:41 UTC

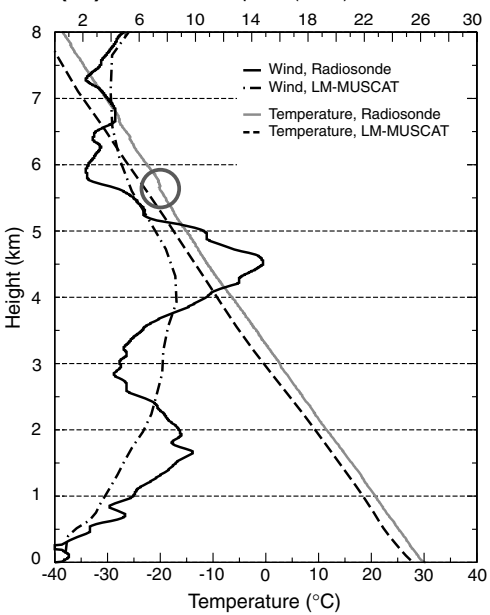

Ouarzazate, $30.93^{\circ} \mathrm{N}, 6.90^{\circ}$

(d)

4 June 2006, 10:39 UTC

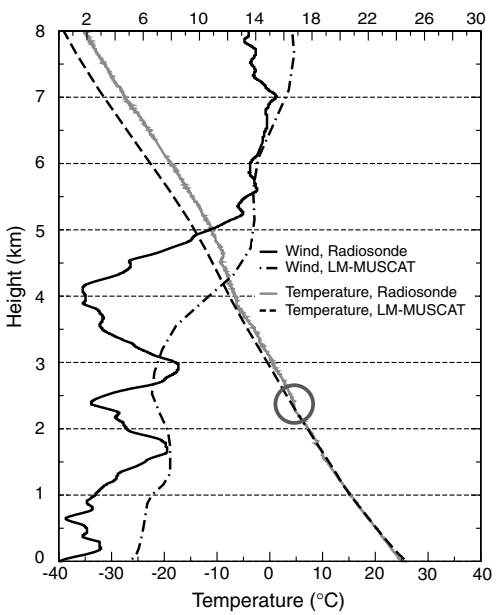

Fig. 4. Vertical profiles of temperature and wind above ground level measured aboard Falcon aircraft flying over Casablanca airport on 20 May 2006 (10:35 UTC, a) and 4 June 2006 (9:19 UTC, c) as well as from radiosondes launched at Ouarzazate on 20 May 2006 (10:41 UTC, b) and 4 June 2006 (10:39 UTC, d) in comparison with model results. Grey circles mark the position of regions of slightly increased thermal stratification that coincide with the dust layer tops shown in Figs. 5 and 6.
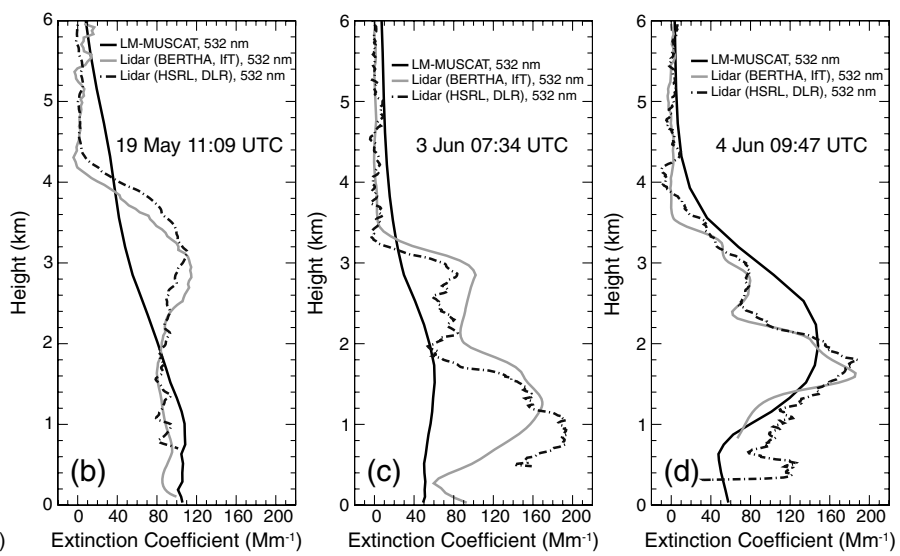

Fig. 5. Vertical distribution of Saharan dust extinction coefficient $(532 \mathrm{~nm})$ above the SAMUM site Ouarzazate above ground level on 18 (21:15 UTC, a) and 19 May 2006 (11:09 UTC, b) as well as on 3 (07:34 UTC, c) and 4 June 2006 (09:47 UTC, d). Comparison of modelled profiles (black solid line) with lidar data from HSRL aboard aircraft Falcon (black dashed-dotted line) and the BERTHA (IfT) lidar (grey line). 
over Ouarzazate was about $50-60 \mathrm{Mm}^{-1}$ in $2.5-3.8 \mathrm{~km}$ above ground level (a.g.1.). The relatively constant extinction coefficient measurements between 2 and $4 \mathrm{~km}$ indicate the presence of a well-mixed dust layer. The model reproduces the magnitude of the dust profile on 18 May except the strong decrease at the top of the dust layer. In the model, dust mixes too efficiently to heights of about $7 \mathrm{~km}$ a.g.1., probably due to the inability of the $\mathrm{LM}$ to reproduce the inversions present in the atmosphere. Below $1.5 \mathrm{~km}$ the model simulates dust extinction coefficients up to $80 \mathrm{Mm}^{-1}$ due to the occurrence of local sources. On the other $3 \mathrm{~d}$, observations are available from the IfT ground lidar and the DLR HSRL lidar aboard the Falcon aircraft. The observations show a maximum of the dust layer at $3 \mathrm{~km}$ a.g.l. [corresponding to $4 \mathrm{~km}$ above sea level (a.s.l.)], with a maximum dust extinction coefficient of about $115 \mathrm{Mm}^{-1}$ on 19 May. Below this maximum the extinction coefficient was at approximately $80 \mathrm{Mm}^{-1}$. Within this range the model results agree well with the observations below $2 \mathrm{~km}$ a.g.l., but the observed maximum at $3 \mathrm{~km}$ is not reached. This mismatch again is likely caused by a dust source in Mali that is not reproduced correctly by the model. Also, as on the previous day, above $3 \mathrm{~km}$ the modelled dust extinction decreases too slowly with height.

During the second period, on 3 June (7:45 UTC), the two lidar measurements show a dust layer with a maximum extinction coefficient of about $190 \mathrm{Mm}^{-1}$ at about $1 \mathrm{~km}$ a.g.l. (2 km a.s.l.) (HSRL) and about $170 \mathrm{Mm}^{-1}$ at about $1.3 \mathrm{~km}$ a.g.l. (IfT, 532 $\mathrm{nm})$. On this day the dust layer reached a depth of about $3 \mathrm{~km}$. The agreement of the model results with the measurements is low, as the simulations result in extinction coefficients of up to $60 \mathrm{Mm}^{-1}$ only. The modelled maximum of the dust layer is at about $1.6 \mathrm{~km}$ height a.g.1. On 4 June (9:45 UTC) the lidar measurements showed the dust layer with a maximum extinction coefficient of about $190 \mathrm{Mm}^{-1}$ at about $1.7 \mathrm{~km}$ a.g.l. The layer reached up to $4 \mathrm{~km}$ a.g.l. On this day the model captures both the magnitude and vertical structure of the dust layer well. The measurements of the two lidar instruments agree better than on the previous day and on 19 May, which is an indication for little temporal variation in the dust layer. This also leads to better agreement between model results and observations on this day.

Lidar backscatter measurements taken in the morning hours by the DLR during the Falcon flight from Casablanca to Ouarzazate on 20 May show an elevated dust layer (Fig. 6a). The vertical distribution of the dust layer can be caused by differential advection during the night and subsequent mixing (Knippertz et al., 2008). The dust layer on 20 May was centred at 5-6 km height a.s.l. to the southeast of the Atlas mountains. The dust originating from Algeria reached across the mountain ridge. On the northwestern side of the Atlas a less pronounced dust layer shows a maximum at about $2.5 \mathrm{~km}$ a.s.l. The dust found at this location originated in Mali and was transported along the Atlantic coast (Fig. 1). The observed region of slightly increased stratification at $5.5 \mathrm{~km}$ height a.g.l. at Ouarzazate (marked in
Fig. 4b) marks the position of the dust layer top on the southeastern side of the Atlas (Fig. 1f). The model overpredicts the dust backscatter coefficient (Figs. 6b and c) to the north of the Atlas mountains and underestimates the dust in the southeast. The model agrees better with the observed vertical structure of the dust layer for the finer horizontal grid resolution of $14 \mathrm{~km}$ (Fig. 6b) compared to $28 \mathrm{~km}$ resolution (Fig. 6c). At higher grid resolution the vertical dust layer structure agrees well between model and observations, except that the modelled dust distribution does not decrease as strongly at $6 \mathrm{~km}$ as observed by the lidar measurements.

On the morning of 4 June (Fig. 7), to the south of the Atlas the maximum of the dust layer was at $3 \mathrm{~km}$ height a.s.l., reaching across the Atlas mountain. Its top coincided with the observed rather weak inversion at $2.5 \mathrm{~km}$ height a.g.l. at Ouarzazate (marked in Fig. 4d). To the north of the Atlas, the dust maximum was at $2 \mathrm{~km}$ height a.s.l. This vertical structure is reproduced by the model results for both 14 and $28 \mathrm{~km}$ grid resolutions (Figs. 7b and c, respectively). In the model the observed inversions are not reproduced, which again may explain the unresolved strong gradient in dust load at the dust layer top. The downward mixing of dust to the north of the Atlas is simulated by the model. However, in contrast to the observations, dust is not mixed down southeast of the Atlas chain in the model. The vertical distribution of the dust backscatter coefficient for the different grid resolutions varies significantly. On $14 \mathrm{~km}$ grid resolution the dust load is overestimated in the layer to the southeast of the Atlas and near the ground to the north. As expected, higher wind speeds are simulated with $14 \mathrm{~km}$ grid spacing allowing the activation of additional dust sources or the computation of higher dust emission fluxes compared to the run with coarser resolution. In this case the higher resolution does not improve the model results with respect to the intensity.

The comparison of the regional dust model results for dust extinction and backscatter at several southern European EARLINET lidar sites is described by Müller et al. (2008a), who find that the model correctly reproduces the maxima of the extinction coefficients at most stations, but some details such as the strong gradient in dust extinction at the top of the dust layer remains unresolved.

\subsection{Dust particle size distribution}

In addition to the spatio-temporal distribution of dust optical thickness and extinction coefficients, the particle size distribution of dust is a good indicator as to whether the dust production and transport processes are correctly reproduced by the model. For 20 May (12:00 UTC), near-surface dust number size distribution from model results agree well with ground measurements from a combined DMPS and APS at Tinfou (Fig. 8a). Mineral dust particles are generally to be found in the size range beyond $0.1 \mu \mathrm{m}$ diameter (e.g. Schütz et al., 1981). So, in the measurements, the high number of particles smaller than $0.1 \mu \mathrm{m}$ is most 
HSRL Aerosol Backscatter Coefficient / $\left(\mathrm{km}^{*} \mathrm{sr}\right)^{\wedge}-1$ at $532 \mathrm{~nm}$
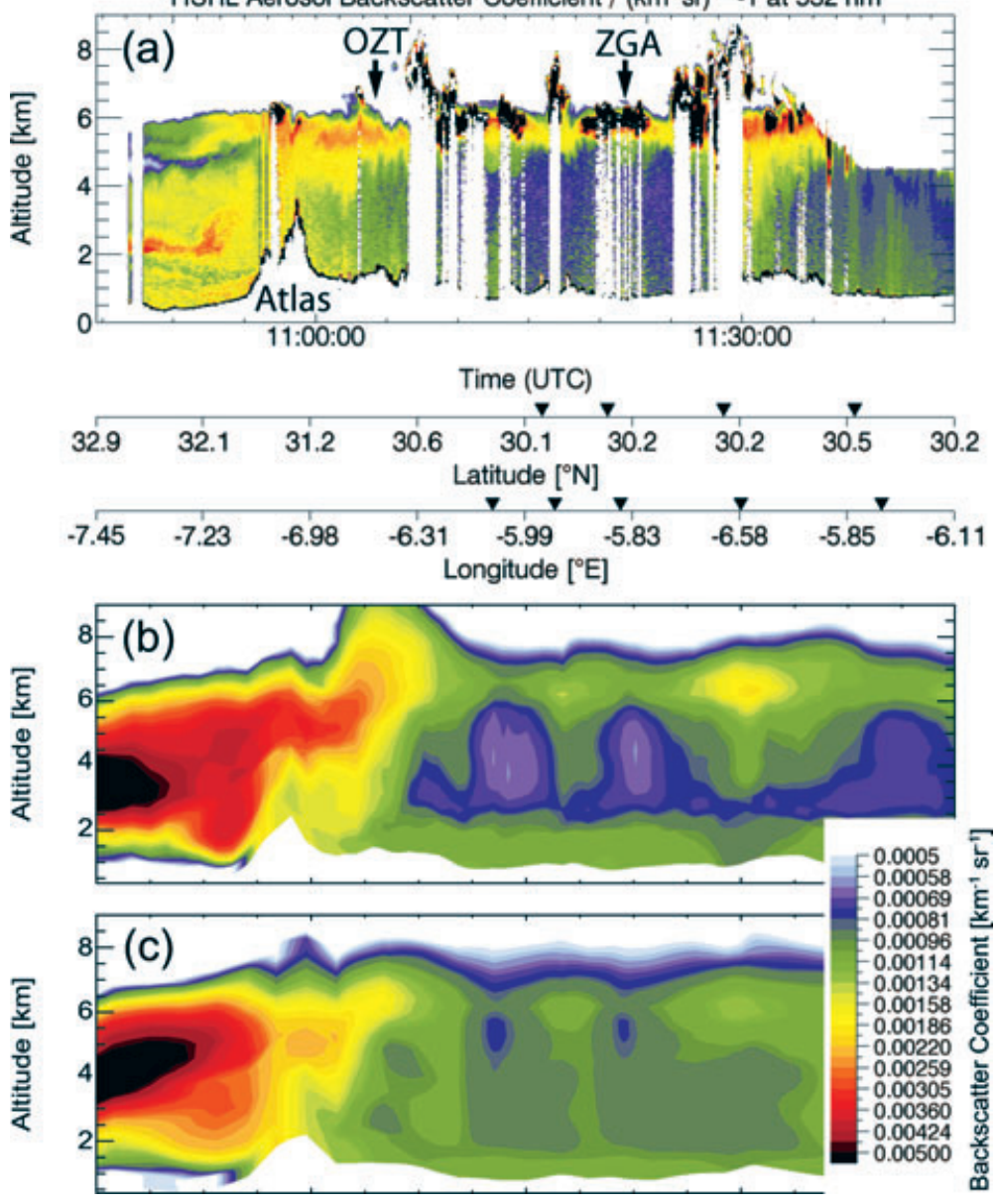

Fig. 6. Vertical distribution of Saharan dust backscatter coefficient above sea level during the Falcon flight from Casablanca (CSB) to Ouarzazate (OZT) via Zagora (ZGA, near Tinfou) on 20 May 2006 (10:45-11:45 UTC). Lidar data from flight measurements (a) and model-derived backscatter coefficient at $14 \mathrm{~km} \mathrm{(b)} \mathrm{and} 28$ $\mathrm{km}$ horizontal resolution (c). Arrows on the longitude/latitude axis indicate changes in the flight direction of the aircraft. The colour bar and axis labels refer to all cross sections. likely not related to dust concentrations. The high number concentration of particles larger than $15 \mu \mathrm{m}$ is an evidence for a surface saltation mode from local dust emissions (Kandler et al., 2008). Here, the discrepancies between the observed and modelled size distribution can be explained by the fact that model results are representative for the first model layer (about $35 \mathrm{~m}$ a.g.1.) while the measurements were taken at $5 \mathrm{~m}$ a.g.l. or more likely that no dust is produced in this location in the model. The observed dust was likely emitted during a dry convective event (dust devils; T. Müller, personal communication) which the model cannot resolve at 28 or $14 \mathrm{~km}$ grid resolution. Particle size measurements on the Falcon aircraft were performed at approximately 13:00 UTC on the same day and are shown for altitudes of $3247 \mathrm{~m}$ a.s.1. (060520a/L08) and $5176 \mathrm{~m}$ a.s.1. (060520a/L07), respectively (Figs. $8 \mathrm{~b}$ and c). The size distribution from measurements were parametrised by fitting multimodal log-normal distributions (Weinzierl et al., 2008). The particle number concentration $\left(N_{i}\right)$ and the count median diameter $\left(C M D_{i}\right)$ together with the standard deviation of the four log-normal modes $i=$ 1-4 are summarised in Weinzierl et al. (2008). At higher altitudes the number of particles with diameters smaller than $40 \mu \mathrm{m}$ was higher than at the surface level on 20 May, as evident in both observations and model results. This finding agrees with the maximum dust concentration observed at about 5-6 km on this day (see also in Fig. 6). In 3247 and $5176 \mathrm{~m}$ a.s.l., the model matches the size distribution of particles smaller than $5 \mu \mathrm{m}$ fairly well, but underestimates the dust number concentrations for larger particles.

On 3 June the agreement in dust particle number size distribution between model and observations at the surface at Tinfou is reasonable. Here, the model overestimates in particular dust concentrations of particle diameter sizes around $10 \mu \mathrm{m}$ (Fig. 9c). The model results reproduce the measurements very well on 4 June, when the dust optical thickness and profiles are modelled realistically (Figs. 9c and f). Model results were also compared with measurements from the Falcon aircraft at about 2 and 3 $\mathrm{km}$ heights on both days (Figs. 9a, b, d and e). On 4 June the number of particles smaller than about $30 \mu \mathrm{m}$ was lower at the surface than in the dust layer in about $2 \mathrm{~km}$ ( 3 June) and $3 \mathrm{~km}$ (4 June), but higher number concentrations for particles larger than $30 \mu \mathrm{m}$ at the surface were due to the vicinity to the dust source. On 3 June, larger particles were observed in $2487 \mathrm{~m}$ a.s.1. $(060603 \mathrm{~b} / \mathrm{L} 07)\left(C M D_{4}=5.0 \mu \mathrm{m}\right)$ than in 3816 $\mathrm{m}$ a.s.l. $(060603 \mathrm{~b} / \mathrm{L} 06)\left(C M D_{4}=2.5 \mu \mathrm{m}\right)$. On the other hand, 
Fig. 7. Vertical distribution of Saharan dust backscatter coefficient above sea level during the Falcon flight from Casablanca (CSB) to Ouarzazate (OZT) on 4 June 2006 (09:18-10:34 UTC). Lidar data from flight measurements (a) and model-derived backscatter coefficient at $14 \mathrm{~km}$ (b) and 28 $\mathrm{km}$ horizontal resolution (c). Arrows on the longitude/latitude axis indicate changes in the flight direction of the aircraft. The colour bar and axis labels refer to all cross sections.
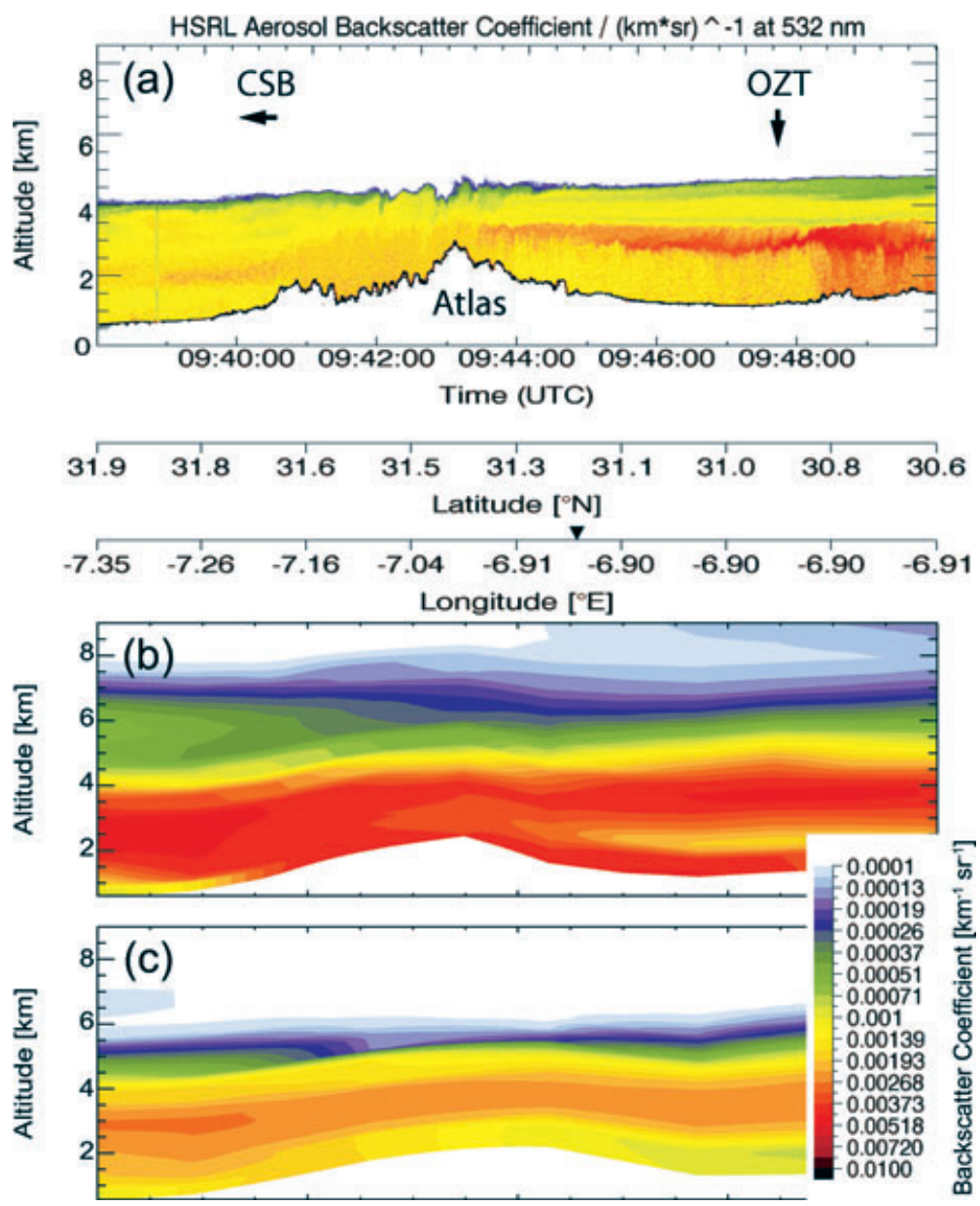

Tinfou $30.3^{\circ} \mathrm{N}, 5.6^{\circ} \mathrm{W}$

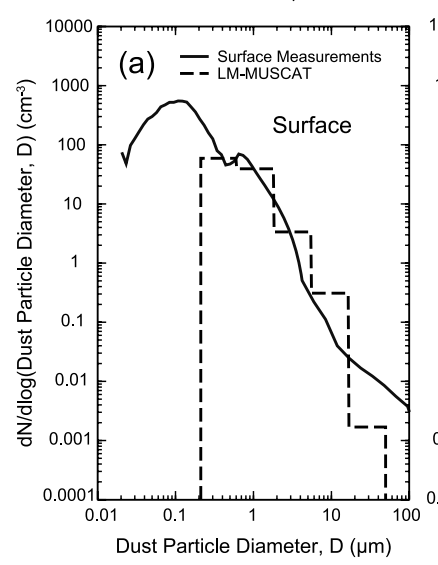

Ouarzazate, 12:55-13:10 UTC Ouarzazate, 12:42-12:50 UTC
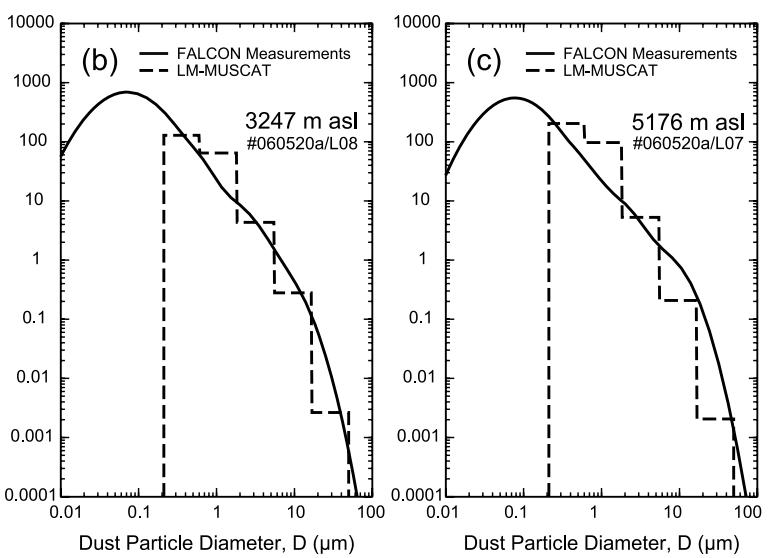

Fig. 8. Ground-level number size distribution at the SAMUM site Tinfou on 20 May 2006 (12:00 UTC). Model results for the first layer at about 35 $\mathrm{m}$ height (dashed line), measurements from a combined DMPS/APS system at about $5 \mathrm{~m}$ height (solid line) (a). Comparison of the number size distribution above Ouarzazate at different heights on 20 May 2006 (around 13:00 UTC; b, c). Particle size distribution from airborne measurements aboard Falcon aircraft (solid line) and model results (dashed line). 

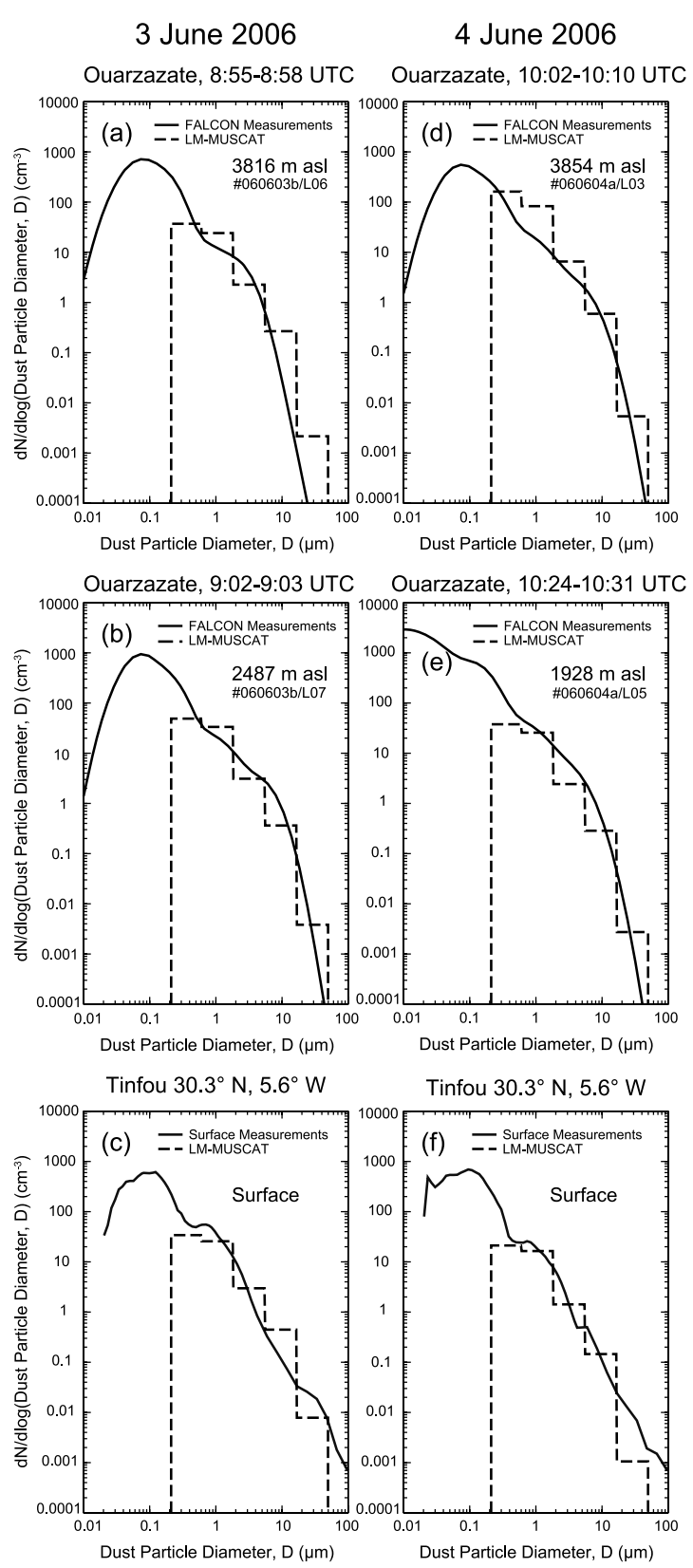

Fig. 9. Comparison of the number size distribution above Ouarzazate at different heights on 3 June 2006 (around 9:00 UTU; a, b) and 4 June 2006 (around 10:00 UTC; d, e). Particle size distribution from airborne measurements aboard Falcon aircraft (solid line) and model results (dashed line). Ground-level number size distribution at the SAMUM site Tinfou on 3 June (11:13 UTC) and 4 June 2006 (9:50 UTC). Model results of the first layer at about $35 \mathrm{~m}$ height (dashed line), measurements from a combined DMPS/APS system at about $5 \mathrm{~m}$ height (solid line) (c, f).

larger particles were observed at $3854 \mathrm{~m}$ a.s.1. (060604a/L03) $\left(C M D_{4}=4.4 \mu \mathrm{m}\right)$ than at $1928 \mathrm{~m}$ a.s.l. (060604a/L05) $\left(C M D_{4}\right.$ $=3.2 \mu \mathrm{m}$ ) on 4 June. The different size distributions indicate differential advection of dust from different sources or different transport paths, changing from 3 to 4 June. The high number of small particles observed at $1928 \mathrm{~m}$ a.s.l. on 4 June is most likely not related to dust concentrations. The agreement between modelled and observed dust number size distribution is better on 4 June than on 3 June, as the dust distribution is not well captured by the model on this day (see Fig. 5). However, the agreement is very good on 4 June, when the dust layer is correctly placed and the right order of magnitude is simulated by the model. Overall, dust particle number size distributions in the model agree well with the different measurements, and the changes in size distribution in the vertical layers due to dust transported from different sources are well matched. Dust particle number size distributions between model and observations agree best, when the spatio-temporal dust distribution is also modelled correctly (based on comparisons of optical thickness and extinction coefficients). In turn, reliable size distributions are needed to compute dust optical quantities for model validation.

\subsection{Evaluation of surface wind speeds}

Most discrepancies between dust optical thickness and extinction coefficients from model results and observations can be explained by an incorrect placement and strength of the dust source in the model. On individual dust days, the spatio-temporal variability of dust emission is closely linked to variability in surface wind speeds responsible for dust emission fluxes from a given area. Comparing simulated surface wind speeds with wind measurements at the IMPETUS stations Iriki, El Miyit and Taoujgalt (measured at $3 \mathrm{~m}$ a.g.l., hourly averages; Figs. 10a-c) and 10-m winds at the WMO stations Tamanrasset, El Golea and Bechar (measured 3-hourly at $10 \mathrm{~m}$ a.g.l.; Figs. 10d-f) provides insight into the model ability to reproduce the surface wind speeds satisfactorily. The modelled 3-m wind speeds were computed from the instantaneous LM first layer wind speeds at hourly resolution assuming neutral conditions and surface roughness from remote sensing (Marticorena et al., 2004). While at Iriki (correlation coefficient $R=0.67$ ), which is located on a plain in the lower Drâa valley, and at Taoujgalt ( $R=0.77$ ), situated in a basin in the High Atlas foothills, the model appears to be capable of reproducing the surface winds for the days 16-22 May, at the station El Miyit $(R=0.43)$ the model underestimates wind speeds due to the complex terrain of the Drâa valley that remains unresolved by the model (Figs. 10a-c). At the WMO station El Golea (located at the western edge of the Great Western Erg, in flat terrain at 337 $\mathrm{m}$ a.s.1.), the agreement between model and observed surface winds is reasonable for low wind speeds $(R=0.65)$; again the model underestimates wind speeds above approximately $6 \mathrm{~m}$ $\mathrm{s}^{-1}$ by up to $30 \%$ (Fig. 10e). In Bechar located at the foothills of the High Atlas at $789 \mathrm{~m}$ a.s.l. and in Tamanrasset situated in the Ahaggar at $1364 \mathrm{~m}$ a.s.l. wind speeds vary strongly with time. The highest measured wind speeds are at $20 \mathrm{~m} \mathrm{~s}^{-1}$. At these locations the simulated wind speeds remain below 


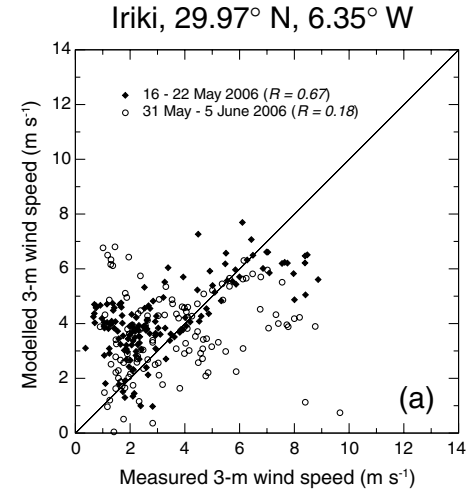

Tamanrasset, $22.78^{\circ} \mathrm{N}, 5.52^{\circ} \mathrm{E}$

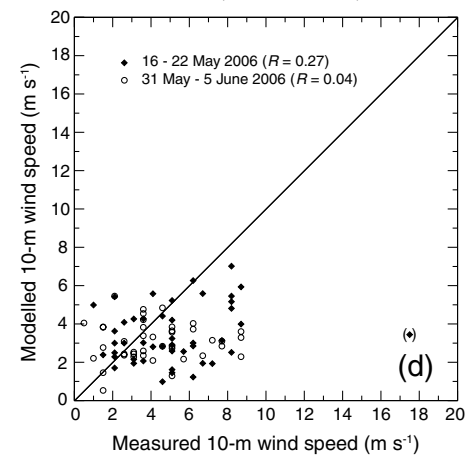

El Miyit, $30.36^{\circ} \mathrm{N}, 5.63^{\circ} \mathrm{W}$

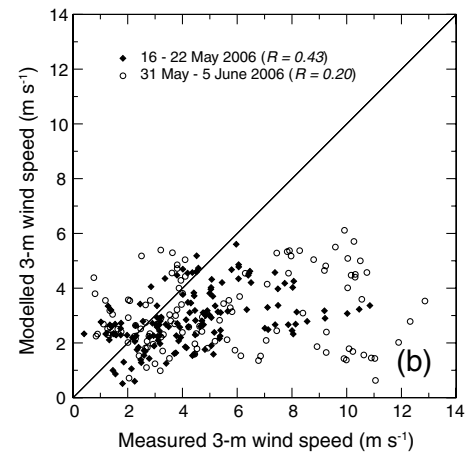

El Golea, $30.57^{\circ} \mathrm{N}, 2.87^{\circ} \mathrm{E}$

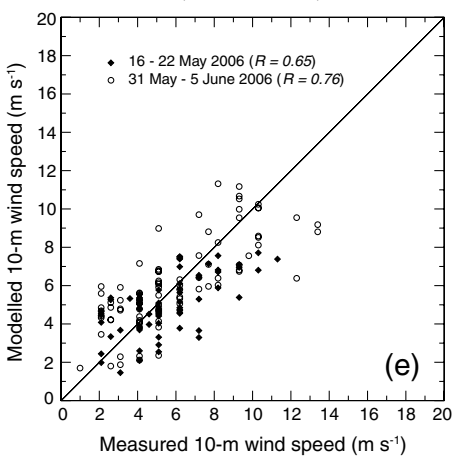

Taoujgalt, $31.39^{\circ} \mathrm{N}, 6.32^{\circ} \mathrm{W}$

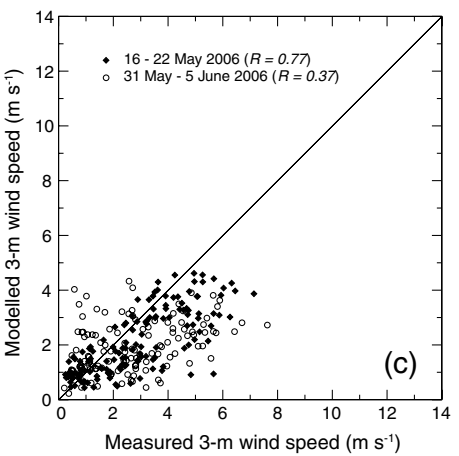

Bechar, $31.15^{\circ} \mathrm{N}, 2.25^{\circ} \mathrm{W}$

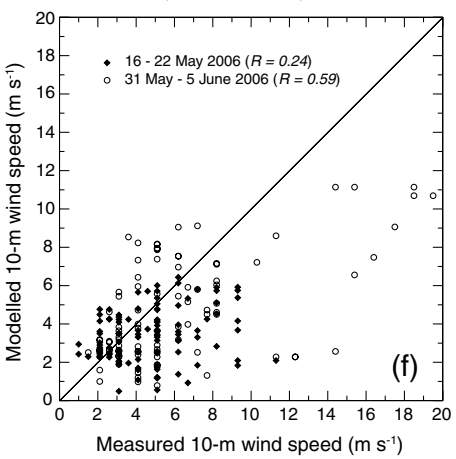

Fig. 10. Comparison of modelled surface winds with the wind speed at $3 \mathrm{~m}$ a.g.l. from the IMPETUS sites: Iriki, El Miyit and Taoujgaltat (a-c) as well as with the wind speed measured at $10 \mathrm{~m}$ a.g.l. at Tamanrasset, El Golea and Bechar (d-f). The results are marked by filled diamonds for the days 16-22 May 2006 and by open circles for 31 May-4 June 2006. Correlation coefficient $R$ in parentheses.

the observations by up to $50 \%$ (Figs. $10 \mathrm{~d}$ and $\mathrm{f}$ ) as indicated by a low correlation coefficient of 0.24 and 0.28 , respectively. Higher wind speeds occurred during the second phase (31 May-4 June), which was characterised by the occurrence of density currents in the Atlas region (Knippertz et al., 2007) that are insufficiently captured by the model (Figs. 10a and c). A better agreement of model results with observations is found at El Golea $(R=$ $0.76)$ and Bechar $(R=0.59)$ for the period 31 May-4 June. While the largest discrepancies occur at El Golea, Bechar and Taoujgalt mainly together with the maximum wind speeds at noon, at El Miyit the underestimations are often related to unresolved orographic winds at night and early in the morning (not shown). The substantial deviations at El Miyit, Tamanrasset and Bechar show that the model is apparently not able to describe the wind conditions over complex mountainous terrain. Insufficient boundary conditions (e.g. model topography) but also unresolved atmospheric processes such as moist convection and density currents most likely account for this inability. However, the $10-\mathrm{m}$ winds are generally underestimated by the model for wind speeds above ca. $6 \mathrm{~m} \mathrm{~s}^{-1}$, which is approximately the wind speed required for initiation of dust emission. In order to compensate for the lower winds and to ensure correct dust production a reduction of the emission threshold velocity is needed for simulations of the SAMUM dust episodes (as also described by Heinold et al. (2007)).

\section{Conclusions}

The performance of the regional dust model system LMMUSCAT-DES was evaluated with measurements of optical thicknesses, extinction coefficients and particle size distributions, as well as satellite dust indices and standard meteorological parameters during the 2006 SAMUM field campaign. The evaluation was done for two time periods in May and June 2006. A particular focus was on the 19 and 20 May as well as on the 3 and 4 June, when many co-located measurements were available. Dust optical thickness and size distributions are mostly well matched by the model. However, the spatio-temporal evolution of the dust plumes was not always satisfactorily reproduced. Much of the disagreement of model results with observations is related to the inaccuracies of the placement of dust sources by the model. While the synoptic-scale meteorology is well matched in the model, maximum surface wind speeds are often underestimated. This problem had already been noted by Heinold et al. (2007) and was addressed by reducing the threshold friction 
velocity needed to initiate dust emissions in the model. A strong mismatch between modelled and observed surface wind speed occurs in areas characterised by strong variations in small-scale topography that cannot be resolved explicitly. Dust sources in the vicinity of such topographic features such as, for example, narrow valleys, are underestimated in the model. While simulated dust distributions are well matched for dust events caused by dry large-scale dynamics, for example, extratropical upper-level troughs and large-scale orographic blocking, the model often misrepresents dust emissions related to moist convective events. The standard LM moist convection scheme by Tiedtke (1989) may not be suitable for the conditions in desert regions. The sensitivity of dust emissions computed by the model with different convection parametrizations is the subject of a follow-up study.

While the model usually places the maximum of the vertical dust layer correctly if source and transport of the dust plume is simulated correctly, the strong gradient of dust extinction coefficients at the top of the dust layer that is observed by lidar instruments is not reproduced, as the dust concentration decreases too gradually with height. The still insufficiently fine resolved spacing of the vertical model layers and an inappropriate boundary layer scheme lead to an absence of inversions in the model vertical profiles, which is the likely cause for the absence of the observed sharply defined dust layers.

The evaluation with the large number of available observations in proximity to dust source regions demonstrates the limits of the regional dust model system. For long-range transport the dust model results often agree well with observations because of mixing of air masses during advection, even if the exact location of the dust sources is not reproduced. When comparing model results with observations near the source regions, such deviations play a more important role when small variations in the source location and transport lead to a shift of advection pathways of dust plumes in the model. It also becomes evident that even if the dust optical thickness is well matched between model and observations, the vertical structure of the dust layer may be different, which can lead to inaccuracies when estimating dust climate effects.

Still, the general features of the dust distribution during the SAMUM field campaign are well matched by the regional dust model system LM-MUSCAT-DES. Dust optical thicknesses, number size distributions and the position of the maximum dust extinction in the vertical profiles agree well with the observations. The generally good model performance makes it a useful tool for the study of direct radiative effects and feedbacks of Saharan dust. While such regional models are well suited for investigations of dust transport during individual case studies that cannot be reproduced by global models, the studies with the high-resolved regional model will ultimately help to improve the parametrizations of global dust models as well.

\section{Acknowledgments}

The present study was supported by the German Research Foundation within the Research Group SAMUM (Saharan Mineral Dust Experiment). We thank J. Cuesta, B. Mougenot, B. Duchenin, S. Pugnaghi and R. Santangelo for kindly providing AERONET data. The IMPETUS project is supported by the Federal German Ministry of Education and Research under grant 01LW06001B and by the Ministry of Innovation, Science, Research and Technology of the federal state of NorthrhineWestfalia under grant 313-21200200. Responsible for the IMPETUS automatic weather stations monitoring network is O. Schulz (Section of Climatology and Landscape Ecology, M. Winiger and J. Loeffler) at the Department of Geography, University of Bonn. The OMI images and data used in this study were acquired using the GES-DISC Interactive Online Visualization ANd aNalysis Infrastructure (Giovanni) as part of the NASA's Goddard Earth Sciences (GES) Data and Information Services Center (DISC). Part of the radiosondes launched in Ouarzazate were funded by the Forschungsfond of the University of Mainz. We also acknowledge good cooperation and support from the German weather service 'Deutscher Wetterdienst' (DWD) and the John von Neumann Institute for Computing (Jülich).

\section{References}

Althausen, D., Müller, D., Ansmann, A., Wandinger, U., Hube, H. and co-authors. 2000. Scanning 6-wavelength 11-channel aerosol lidar. J. Atmos. Oceanic Technol. 17, 1469-1482.

Berge, E. 1997. Transboundary air pollution in Europe. In: $M S C-W$ Status Report 1997, Part 1 and 2, EMEP/MSC-W Report 1/97, The Norwegian Meteorological Institute, Oslo.

Doms, G. and Schättler, U. 2002. A Description of the Nonhydrostatic Regional Model LM. Tech. Rep. Part I: dynamics and Numerics, Deutscher Wetterdienst, Deutscher Wetterdienst, Offenbach, Germany . Available at http://www.cosmo-model.org/.

Esselborn, M., Wirth, M., Fix, A., Weinzierl, B., Rasp, K. and co-authors. 2008. Spatial distribution and optical properties of Saharan dust observed by airborne high spectral resolution lidar during SAMUM 2006. Tellus 61B, doi:10.1111/j.1600-0889.2008.00394.x.

Heinold, B., Helmert, J., Hellmuth, O., Wolke, R., Ansmann, A. and co-authors. 2007. Regional modeling of Saharan dust events using LM-MUSCAT: Model description and case studies. J. Geophys. Res. 112, D11204, doi:10.1029/2006JD007443.

Heintzenberg, J. 2008. The SAMUM-1 experiment over Southern Morocco: overview and introduction. Tellus 61B, doi:10.1111/j.16000889.2008.00403.x.

Helmert, J., Heinold, B., Tegen, I., Hellmuth, O. and Wendisch, M. 2007. On the direct and semi-direct effect of Saharan dust over Europe: A modeling study. J. Geophys. Res. 112, D11204, doi:10.1029/2006JD007444.

Holben, B. N., Eck, T. F., Slutsker, I., Tanre, D., Buis, J. P. and coauthors. 1998. AERONET - a federated instrument network and data archive for aerosol characterisation. Remote Sens. Environ. 66, 1-16. 
IPCC 2007. Climate Change 2007: the Physical Science Basis. Contribution of Working Group I to the Forth Assessment Report of the Intergovernmental Panel on Climate Change (eds S. Solomon and co-editors), Cambridge University Press, New York.

Jakobson, H. A., Jonson, J. E. and Berge, E. 1997. The multi-layer Eulerian model: model description and evaluation of transboundary fluxes of sulphur and nitrogen species for one year. EMEP/MSC-W Note 2/97, The Norwegian Meteorological Institute, Oslo.

Kandler, K., Schütz, L., Deutscher, C., Ebert, M., Hofmann, H. and coauthors. 2008. Size distribution, mass concentration, chemical and mineralogical composition, and derived optical parameters of the boundary layer aerosol at Tinfou, Morocco, during SAMUM 2006. Tellus 61B, doi:10.1111/j.1600-0889.2008.00385.x.

Knippertz, P., Deutscher, C., Kandler, K., Müller, T., Schulz, O. and co-authors. 2007. Dust mobilization due to density currents in the Atlas region: Observations from the Saharan Mineral Dust Experiment 2006 field campaign. J. Geophys. Res. 112, D21109, doi:10.1029/2007JD008774.

Knippertz, P., Ansmann, A., Althausen, D., Müller, D., Tesche, M. and co-authors. 2008. Dust Mobilization and Transport in the Northern Sahara during SAMUM 2006-A Meteorological Overview. Tellus 61B, doi:10.1111/j.1600-0889.2008.00380.x.

Knoth, O. and Wolke, R. 1998. Implicit-explicit Runge-Kutta methods for computing atmospheric reactive flow. Appl. Num. Math. 28, 327341.

Lacis, A. A. and Mishchenko, M. I. 1995. Climate forcing, climate sensitivity, and climate response: a radiative modeling perspective on atmospheric aerosols. In: Aerosol Forcing of Climate: Report of the Dahlem Workshop on Aerosol Forcing of Climate (eds J. R. Charlson and J. Heintzenberg), John Wiley, Hoboken, 11-42.

Levelt, R. F. 2002. OMI Algorithm Theoretical Basis Document Volume 1: OMI Instrument, Level 0-1b processor, calibration \& operations, technical report. NASA Goddard Space Flight Center, Greenbelt, Md.

Majewski, D., Liermann, D., Prohl, P., Ritter, B., Buchhold, M. and co-authors. 2002, The operational global icosahedral-hexagonal gridpoint model GME: Description and high-resolution tests. Mon. Wea. Rev. 130(2), 319-338.

Marticorena, B. and Bergametti, G. 1995, Modeling the atmospheric dust cycle: 1 . Design of a soil-derived dust emission scheme. J. Geophys. Res. 100, 16415-16430.

Marticorena, B., Chazette, P., Bergametti, G., Dulac, F. and Legrand, M. 2004. Mapping the aerodynamic roughness length of desert surfaces from the POLDER/ADEOS bi-directional reflectance product. Int. J. Remote Sens. 25, 603-626.

Miller, R. L., Perlwitz, J. and Tegen, I. 2004. Feedback upon dust emission by dust radiative forcing through the planetary boundary layer. J. Geophys. Res. 109(D24), D24209, doi:10.1029/2004JD004912.

Müller, D., Heinold, B., Tesche, M., Tegen, I., Althausen, D. and coauthors. 2008a. EARLINET observations of the 14-22-May longrange dust transport event during SAMUM 2006: Validation of results from dust transport modelling. Tellus 61B, doi:10.1111/j.16000889.2008.00400.x.

Müller, T., Schladitz, A., Massling, A., Kaaden, N., Wiedensohler, A. and co-authors. 2008b. Spectral absorption coefficients and imaginary parts of refractive index of Saharan dust during SAMUM-1. Tellus 61B, doi:10.1111/j.1600-0889.2008.00399.x.
Myhre, G., Grini, A., Haywood, J. M., Stordal, F., Chatenet, B., Tanré, D., Sundet, J. K. and Isaksen, I. S. A. 2003. Modeling the radiative impact of mineral dust during the Saharan Dust Experiment (SHADE) campaign. J. Geophys. Res. 108(D18), 8579, doi:10.1029/2002JD002566.

Petzold, A., Rasp, K., Weinzierl, B., Esselborn, M., Hamburger, T. and co-authors. 2008. Saharan dust absorption and refractive index from aircraft-based observations during SAMUM 2006. Tellus 61B, doi:10.1111/j.1600-0889.2008.00383.x.

Prospero, J. M., Ginoux, P., Torres, O., Nicholson, S. E. and Gill, T. E. 2002. Environmental characterization of global sources of atmospheric soil dust identified with the Nimbus 7 Total Ozone Mapping Spectrometer (TOMS) absorbing aerosol product. Rev. Geophys. 40(1), 1002, doi:10.1029/2000RG000095.

Ritter, B. and Geleyn, J. F. 1992. A comprehensive radiation scheme for numerical weather prediction models with potential applications in climate simulations. Mon. Wea. Rev. 120, 303-325.

Schepanski, K., Tegen, I., Laurent, B., Heinold, B. and Macke, A. 2007. A new Saharan dust source activation frequency map derived from MSG-SEVIRI IR-channels. Geophys. Res. Lett. 34, L18803, doi:10.1029/2007GL030168.

Schladitz, A., Müller, T., Kaaden, N., Massling, A., Kandler, K. and coauthors. 2008. In situ measurements of Optical Properties at Tinfou (Morocco) during the Saharan Mineral Dust Experiment SAMUM 2006. Tellus 61B, doi:10.1111/j.1600-0889.2008.00397.x.

Schmetz, J., Pili, P., Tjemkes, S., Just, D., Kerkmann, J. and co-authors. 2002. An introduction to Meteosat Second Generation (MSG). Bull. Amer. Meteor. Soc. 83, 977-992.

Schütz, L., Ruprecht, J. and Pietrek, H. 1981. Saharan dust transport over the North Atlantic Ocean. Geol. Soc. Am. Special Paper 186, 87-100.

Sinyuk, A., Torres, O. and Dubovik, O. 2003. Combined use of satellite and surface observations to infer the imaginary part of refractive index of Saharan dust.. Geophys. Res. Lett. 30(2), 1081, doi:10.1029/2002GL016189.

Speth, P. and Diekkrüger, B. (Eds.), 2006. An integrated approach to the efficient management of scarce water resources in West Africa-case studies for selected river catchments in different climate zones. In: Second Final Report, Period: 01.05.2003-31.07.2006, Institute for Geophysics and Meteorology, University of Cologne, Germany .

Sokolik, I. N. and Toon, O. B. 1996. Direct radiative forcing by anthropogenic airborne mineral aerosols. Nature 381, 681-683.

Sokolik, I. N. and Toon, O. B. 1999. Incorporation of mineralogical composition into models of the radiative properties of mineral aerosol from UV to IR wavelengths. J. Geophys. Res. 104, 94239444.

Tanré, D., Geleyn, J. F. and Slingo, J. M. 1984. First results of the introduction of an advanced aerosol-radiation interaction in the ECMWF low resolution global model. In: Aerosols and Their Climatic Effects (eds H. E. Gerber and A. Deepak), A. Deepak), Hampton, Va., 133177.

Tegen, I., Harrison, S. P., Kohfeld, K., Prentice, I. C., Coe, M and coauthors. 2002. Impact of vegetation and preferential source areas on global dust aerosol: results from a model study. J. Geophys. Res. 107(D21), 4576, doi:10.1029/2001JD000963.

Tegen, I., Heinold, B., Todd, M., Helmert, J., Washington, R. and coauthors. 2006. Modelling soil dust aerosol in the Bodélé depression during the BoDEx campaign. Atmos. Chem. Phys. 6, 4171-4211. 
Tesche, M., Ansmann, A., Müller, D., Althausen, D., Mattis, I. and coauthors. 2008. Vertical profiling of Saharan dust with Raman lidars and airborne HSRL in southern Morocco during SAMUM. Tellus 61B, doi:10.1111/j.1600-0889.2008.00390.x.

Tiedtke, M. 1989. A comprehensive mass flux scheme for cumulus parameterisation in large-scale models.. Mon. Wea. Rev. 117, 17791799.

Washington, R., Todd, M. C., Middleton, N. J. and Goudie, A. S. 2003. Dust-storm source areas determined by the Total Ozone Monitoring Spectrometer and surface observations. Ann. Assoc. Am. Geogr. 93, 297-313.

Weinzierl, B., Petzold, A., Esselborn, M., Wirth, M., Rasp, K. and coauthors. 2008. Airborne measurements of dust layer properties, particle size distribution and mixing state of Saharan dust during SAMUM 2006. Tellus 61B, doi:10.1111/j.1600-0889.2008.00392.x.

Wolke, R. and Knoth, O. 2000. Implicit-explicit Runge-Kutta methods applied to atmospheric chemistry-transport modelling. Environ. Model. Softw. 15, 711-719.

Wolke, R., Hellmuth, O., Knoth, O., Schröder, W., Heinrich, B. and co-authors. 2004a. The chemistry-transport modeling system LMMUSCAT: Description and CityDelta applications. In: Air Pollution Modeling and Its Application XVI (eds C. Borrego and S. Incecik), Proceedings of twenty-sixth NATO/CCMS international tech- nical meeting on air pollution modeling and its application, Kluver Academic/Plenum Publishers, New York.

Wolke, R., Hellmuth, O., Knoth, O., Schröder, W. and Renner, E. 2004b. The parallel model system LM-MUSCAT for chemistry-transport simulations: Coupling scheme, parallelization and application. In: Parallel Computing: Software Technology, Algorithms, Architectures, and Applications, (eds G. R. Joubert, W. E. Nagel, F. J. Peters and W. V. Walter), Advanced in Parallel Computing, Elsevier, the Netherlands, 363-370.

Yoshioka, M., Mahowald, N., Conley, A. J., Collins, W. D., Fillmore, D. W. and co-authors. 2007. Impact of desert dust radiative forcing on Sahel precipitation: relative importance of dust compared to sea surface temperature variations, vegetation changes, and greenhouse gas warming. J. Climate 20(8), 1445-1467.

Zender, C., Newman, D. S. and Torres O. 2003. Spatial heterogeneity in aeolian erodibility: Uniform, topographic, geomorphic, and hydrologic hypotheses. J. Geophys. Res. 108(D17), 4543, doi:10.1029/2002JD003039.

Zhang, L., Gong, S., Padro, J. and Barrie, L. 2001. A size-segregated particle dry deposition scheme for an atmospheric aerosol module. Atmos. Environ. 35, 549-560.

Zobler, L. 1986. A world soil file for global climate modeling. In: NASA Technical Memorandum 87802, 32 pp., NASA, Washington, DC . 